\title{
Disruption of maternal parenting circuitry by addictive process: rewiring of reward and stress systems
}

\author{
Helena J. V. Rutherford ${ }^{1,+}{ }^{*}$, Sarah K. Williams ${ }^{2,+}{ }^{*}$, Sheryl Moy ${ }^{2,3}$, Linda C. Mayes ${ }^{1}$ and Josephine M. Johns ${ }^{2,3}$ \\ ${ }^{1}$ Yale Child Study Center, Yale University, New Haven, CT, USA \\ ${ }^{2}$ Department of Psychiatry, University of North Carolina-Chapel Hill, Chapel Hill, NC, USA \\ ${ }^{3}$ Carolina Institute for Developmental Disabilities, University of North Carolina-Chapel Hill, Chapel Hill, NC, USA
}

Edited by:

Rina Eiden, University at Buffalo, USA

Reviewed by:

Sue Carter, University of Illinois at

Chicago, USA

Kelly Lambert, Randolph-Macon

College, USA

\section{*Correspondence.}

Helena J. V. Rutherford, Yale Child Study Center, Yale University, 230 South Frontage Road, New Haven, CT 06520, USA.

e-mail: helena.rutherford@yale.edu; Sarah K. Williams, Department of Psychiatry, University of North Carolina-Chapel Hill, 436 Taylor Hall, CB \# 7096, Chapel Hill, NC 27599, USA

e-mail: sarahk_williams@med.unc.edu ${ }^{\dagger}$ Helena J. V. Rutherford and Sarah K. Williams share first-authorship.
Addiction represents a complex interaction between the reward and stress neural circuits, with increasing drug use reflecting a shift from positive reinforcement to negative reinforcement mechanisms in sustaining drug dependence. Preclinical studies have indicated the involvement of regions within the extended amygdala as subserving this transition, especially under stressful conditions. In the addictive situation, the reward system serves to maintain habitual behaviors that are associated with the relief of negative affect, at the cost of attenuating the salience of other rewards. Therefore, addiction reflects the dysregulation between core reward systems, including the prefrontal cortex (PFC), ventral tegmental area (VTA), and nucleus accumbens (NAc), as well as the hypothalamic-pituitary-adrenal axis and extended amygdala of the stress system. Here, we consider the consequences of changes in neural function during or following addiction on parenting, an inherently rewarding process that may be disrupted by addiction. Specifically, we outline the preclinical and human studies that support the dysregulation of reward and stress systems by addiction and the contribution of these systems to parenting. Increasing evidence suggests an important role for the hypothalamus, PFC, VTA, and NAc in parenting, with these same regions being those dysregulated in addiction. Moreover, in addicted adults, we propose that parenting cues trigger stress reactivity rather than reward salience, and this may heighten negative affect states, eliciting both addictive behaviors and the potential for child neglect and abuse.

Keywords: addiction, reward, stress, parenting, preclinical, human
Addiction has been conceptualized as a cyclic process of impairment in self-regulation. Both positive and negative reinforcement mechanisms likely contribute to the maintenance of addiction; the former representing the reward response following initial use, the latter representing continued use for relief of the negative affective state of abstinence. At a neurobiological level, while activation of the brain reward system underscores drug use (i.e., positive reinforcement), the activation of the brain stress system may govern the distress associated with withdrawal (i.e., negative reinforcement). In the addictive situation, the relief of stress by the drug leads to habitual drug use, and the reward system is "co-opted" for purposes of maintaining habitual behavior that is linked to relief of stress or negative emotions. With this co-optation, other more adaptive rewards are not as salient because they are not part of the conditioned stress relief-reward link. Importantly, these rewards include social affiliation and relationships, and this kind of co-optation has profound implications for parenting behaviors among addicted adults, and indeed for their relationships in general. In these instances, relationships may become more stressful for the addicted adult because of the demands for care. Hence, instead of the normative rewards offered by affiliation, the relationship becomes more stressful and serves as a cue for continued compulsive or addictive behavior while perpetuating social or maternal avoidance behavior.
In this paper, we will outline the evidence from preclinical and human studies to address the following propositions outlined in Figure 1: (a) addictive processes are a reflection of a dysregulation of the balance between reward systems and the stress response; (b) parenting involves a special adaptation of both reward and stress regulatory neural systems to the relevant cues from offspring that become highly salient for the adult, now a parent; and (c) in the addictive situation, parenting cues are not rewarding but instead stressful. This heightened stress response may promote drug-seeking behaviors rather than parenting behaviors and attending to the infant's needs. We focus on cocaine addiction to explore the evidence for this model.

\section{COCAINE DISRUPTS MATERNAL BEHAVIOR: EVIDENCE FROM RODENT AND HUMAN DATA}

Cocaine use and abuse represents a significant public health problem. In 2008, 1.4 million Americans met DSM-IV criteria for drug abuse and dependency for their cocaine addiction (Substance Abuse and Mental Health Services Administration, 2008). Rates of cocaine use in young women have increased, and a number of studies have reported cocaine use during pregnancy (Kuczkowski, 2004). Continued cocaine use into the postpartum period is not uncommon and presents significant problems for parenting practice; specifically, maternal substance abuse is associated 


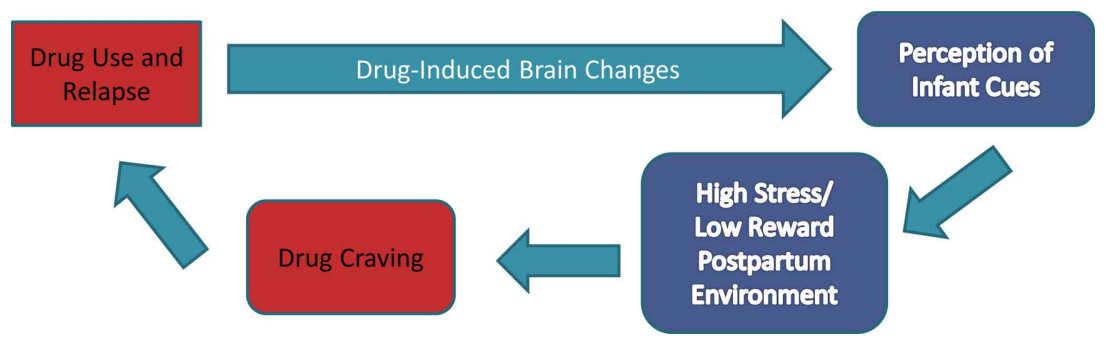

FIGURE 1 |The relationship between addiction and parenting. In our model, addiction represents the dysregulation of stress and reward systems, both of which are adapted to support parenting. In the addicted situation we propose that drug-induced brain changes result in the rewarding value of infant cues being attenuated, replaced by a more stressful neurophysiological response. This stress response to infant cues may increase craving for drugs of abuse, promoting drug seeking and relapse in abstinent mothers, and perpetuates the cycle of neglect. with significant increases in child neglect (Cash and Wilke, 2003). The complexity of studying cocaine effects on human parenting at behavioral and neurobiological levels is complicated by the breadth of psychosocial and biological variables that are associated with cocaine use and thus, present unique challenges to empirical research. Therefore, we take a complementary approach bridging work from basic science with human studies. Although most mammalian species exhibit some form of parental care toward their young, rodents serve as excellent preclinical models for the study of onset and maintenance of maternal behavior (MB) because, similar to humans, they produce altricial infants requiring an immense commitment in order to ensure survival. The typical rat mother (dam) spends the entire day with pups for 2 weeks postpartum, only leaving the nest to forage for food. Rodents exhibit stereotyped behaviors toward infants (pups) that can be quantified and have behavioral correlates to humans, including nursing and grooming the infant as well as preparing a safe environment for the infant (nest-building). Maternal aggression or defense also emerges during the postpartum period, a behavior that is analogous to "protectiveness" experienced by new human mothers. We begin this paper by considering the empirical support of cocaine disruption to $\mathrm{MB}$ in human and rodent studies.

In human studies, the consequences of cocaine exposure and administration on parenting have been explored primarily through observations of mother-child interactions. Within 12$48 \mathrm{~h}$ postpartum, mothers who used cocaine during pregnancy responded more passively and were more disengaged from their newborn compared to mothers who were drug-free (Gottwald and Thurman, 1994). Early work with infants suggested that mothers using cocaine during pregnancy evidence reduced expression of positive affect and sensitivity to infant cues, as well as poorer creativity and resourcefulness during dyadic interactions (Burns et al., 1991, 1997). There is some evidence to suggest that while early impairments (e.g., reduced attention toward the infant, shifts in attention away from the infant) in mother-child interactions appear modulated by prenatal cocaine exposure, follow up assessments have shown either a reduction (Mayes et al., 1997) or absence of these same dysfunctions (Ball et al., 1997) suggesting the effects of cocaine exposure may change over time. This has prompted studies to explore the effects of prenatal cocaine exposure on maternal interactions in toddlers too, evidencing maladaptive and hostile interactions of dyads with cocaine exposure (Johnson et al., 2002; Uhlhorn et al., 2005; Molitor and Mayes, 2010). The consequences of cocaine use during pregnancy have also been explored during feeding episodes. Poorer feeding interactions were reported in mothers who used cocaine during pregnancy and who relapsed postpartum, compared to mothers who had not relapsed (Blackwell et al., 1998). These feeding dyads demonstrated greater conflict (Eiden, 2001) as well as insensitivity (Eiden et al., 2006) between mother and child. It is important to note that impairments in mother-child interactions may also be related to the amount of cocaine consumed during pregnancy (Tronick et al., 2005), as well as postpartum use (Blackwell et al., 1998; Johnson et al., 2002; Eiden et al., 2006). Although to date there are no published neuroimaging studies in cocaine addicted mothers, initial pilot work suggests differential prefrontal cortex (PFC) activation when viewing infant faces in these women compared to mothers with no cocaine use history (Strathearn and Kosten, 2008).

Studies on mother-infant dynamics in the rodent have shown that exposure to cocaine, through acute, intermittent, or chronic treatment regimens, disrupts aspects of $\mathrm{MB}$, with the extent of disruption dependent on dose, duration, time of testing, and treatment regimen (Johns et al., 1994; Nelson et al., 1998). In one commonly used paradigm, dams receive cocaine either chronically on gestation days (GD 1-20;30 mg/kg) or via single injections during the postpartum period, and are then tested for pup-directed $\mathrm{MB}$ following separation and reunion with pups. Either regimen can lead to increased latency and decreased duration of nursing, along with disruptions in licking and nest-building. Cocaine treated dams also exhibit maladaptive maternal aggressive behavior, indicating that social behavior deficits may extend past pup relationships (Johns et al., 1997b; McMurray et al., 2008).These disruptions are not caused by hyperactivity or cocaine withdrawal (Johns et al., 1997b), suggesting instead alterations in motivational or social interaction circuitry.

In contrast to treatment during gestation, repeated exposure to cocaine before pregnancy increases retrieval and licking behaviors in rats and mice early postpartum, suggesting that adult cocaine exposure alters motivational salience and behavior toward later, naturally rewarding stimuli, such as pups (Nephew and Febo, 2010). However, although these mothers were quicker to retrieve pups, they took longer to initiate other MBs, suggesting that the salience may be in having the pup nearby but not in the act of 
caring for it. Functional magnetic resonance imaging (fMRI) in awake animals has allowed investigation of the activation of brain regions following exposure to rewarding stimuli. Indeed, cocaine pre-exposure also diminished the activation to pup suckling in the medial prefrontal cortex (mPFC), striatum, and auditory cortex, but did not affect baseline dopamine (DA) or percent increase of DA upon exposure to pups in the mPFC (Febo and Ferris, 2007), supporting the important roles in $\mathrm{MB}$ and addiction processes these regions hold, a point we will return to later in this review.

Taken together, these findings indicate that cocaine use before, during, and/or after pregnancy can significantly alter $\mathrm{MB}$ in the postpartum period. Since MB is not entirely abolished, we propose that these behavioral changes may indicate differences in the reward salience of offspring. Additionally, the transition from pregnancy to the postpartum is inherently stressful to mothers; however, the successful adaptation to this new environment may be considered under the control of allostatic mechanisms. Allostasis has been defined as the active process of responding to challenges from the environment to maintain homeostasis, usually through activation of hormonal stress responses. Successful adaptation to this stressful environment and the ability to respond appropriately to an infant's needs is critical for the infant's survival and thus has been conserved throughout mammalian evolution. It has been proposed that drug addiction can disrupt typical adaptation to stressful non-parenting environments (Le Moal, 2009); however, whether the same is true for the postpartum period remains unclear and offers a potential explanation for the drug-induced deficits described above. The review presented here considers the involvement of neural structures in both the reward and stress systems in parenting (outlined in Figure 2).

\section{INITIATION OF MATERNAL BEHAVIOR}

Central to this review is the notion that there are significant neurobiological changes subserving the transition to parenthood. These include a variety of structural and neurochemical changes indicating plasticity both at the synaptic and transcriptional regulation levels of control. Throughout this paper we refer to changes in neuronal function, receptor expression, or peptide levels, as a result either from motherhood or drug exposure, as plastic to indicate the dynamic nature of neurons. Critical to the transition to motherhood are significant changes in the function of the hypothalamus and the production of the neuropeptide oxytocin (OT), and therefore we first consider the initiation of $\mathrm{MB}$ and the involvement of the hypothalamus and oxytocin before reviewing the stress and reward neural circuitry and their adaptation for parenting.

\section{HYPOTHALAMUS}

The medial preoptic area (MPOA) and ventral bed nucleus of the stria terminalis (BNST) are critical for the initiation and maintenance of $\mathrm{MB}$, and represent a directing region controlling the switch to parental behaviors (Numan, 2007). The MPOA has direct connections to the ventral tegmental area (VTA), nucleus accumbens (NAc), mPFC, BNST, and paraventricular nucleus (PVN), allowing it to exert a powerful influence during the postpartum period. Lesions to the MPOA completely abolish retrieval and nest-building behaviors in rats. Nursing is still observed following lesions, though it is diminished, and may be the result of pups seeking out and attaching to a non-responsive dam. These results indicate that the MPOA is important for the incentive actions in MB (Numan, 2007). Increased MPOA neuronal activation, as measured by c-FOS, CREB, and AMRI, is observed following exposure to pups and pup cues in the first 2 postpartum weeks (Fleming and Korsmit, 1996; Febo et al., 2005; Jin et al., 2005). Notably, deficiency of CREB in mouse mutant lines leads to increases in pup mortality and significant deficits in latency to retrieve pups and in the number of pups brought back to the nest (Jin et al., 2005). DA and serotonin (5-HT) maintain baseline levels in this region across pregnancy, however norepinephrine (NE) is decreased during this period (Olazabal et al., 2004). Overall, the results suggest that CREB activation in the MPOA could be especially important for the initiation and expression of $\mathrm{MB}$. Converging with this in human mothers, individual differences in maternal sensitivity to infant cues revealed differential modulation of the hypothalamus, as well as pituitary and PFC regions, when the mothers were viewing photographs of their own infants, compared to unknown infants (Strathearn et al., 2009). Moreover, in this latter study, maternal OT response following a play interaction correlated with activity in the hypothalamus (as well as the pituitary and ventral striatum).

\section{OXYTOCIN}

Oxytocin plays a central role in initiating the onset of $\mathrm{MB}$ in several mammalian species, including the rat and human, but its role in maintenance of $\mathrm{MB}$ is less clear (Pedersen and Boccia, 2002; Feldman et al., 2007). In the rodent, OT neurons from the PVN project centrally to the main olfactory bulb (MOB), MPOA, NAc, amygdala (AMY), hippocampus, and VTA (see Figure 3). OT from the PVN and supraoptic nucleus (SON) project to the pituitary for peripheral release into the bloodstream in response to infant-produced or stressful stimuli (Uvnas-Moberg et al., 2005; Hatton and Wang, 2008). Work using mouse lines null for OT have demonstrated that OT is essential for survival of litters due to effects on milk ejection, but may not be critical for other aspects of maternal responses (Lee et al., 2009). Although OT null-mutants have normal reproductive and nurturing responses (Ferguson et al., 2000, 2001), mouse dams with targeted disruption of the OT receptor gene have significant deficits in pup retrieval, including longer latencies to retrieve each pup and to assume a crouching posture, and shorter time spent crouching over the pups (Takayanagi et al., 2005). Additionally, human mothers with a low functioning OT receptor allele show lower maternal sensitivity in the postpartum (Bakermans-Kranenburg and van Ijzendoorn, 2008). Alterations in OT function have been suggested to underlie maternal deficits in mice with a mutation in Peg3 (Paternally expressed gene 3). Female Peg3 mutant mice have severe impairments in $\mathrm{MB}$ and deficient milk let-down (Champagne et al., 2009). These deficits have been linked to reductions in OT neurons in the hypothalamus and decreased OT binding in the MPOA and lateral septum in Peg3 mutants (Champagne et al., 2009).

A recent paper by Yoshida et al. (2009) suggested that an underlying mechanism for OT effects on social and anxiety-like behavior is enhanced serotonergic neurotransmission. Central administration of OT to the median raphe nucleus led to significant release of 


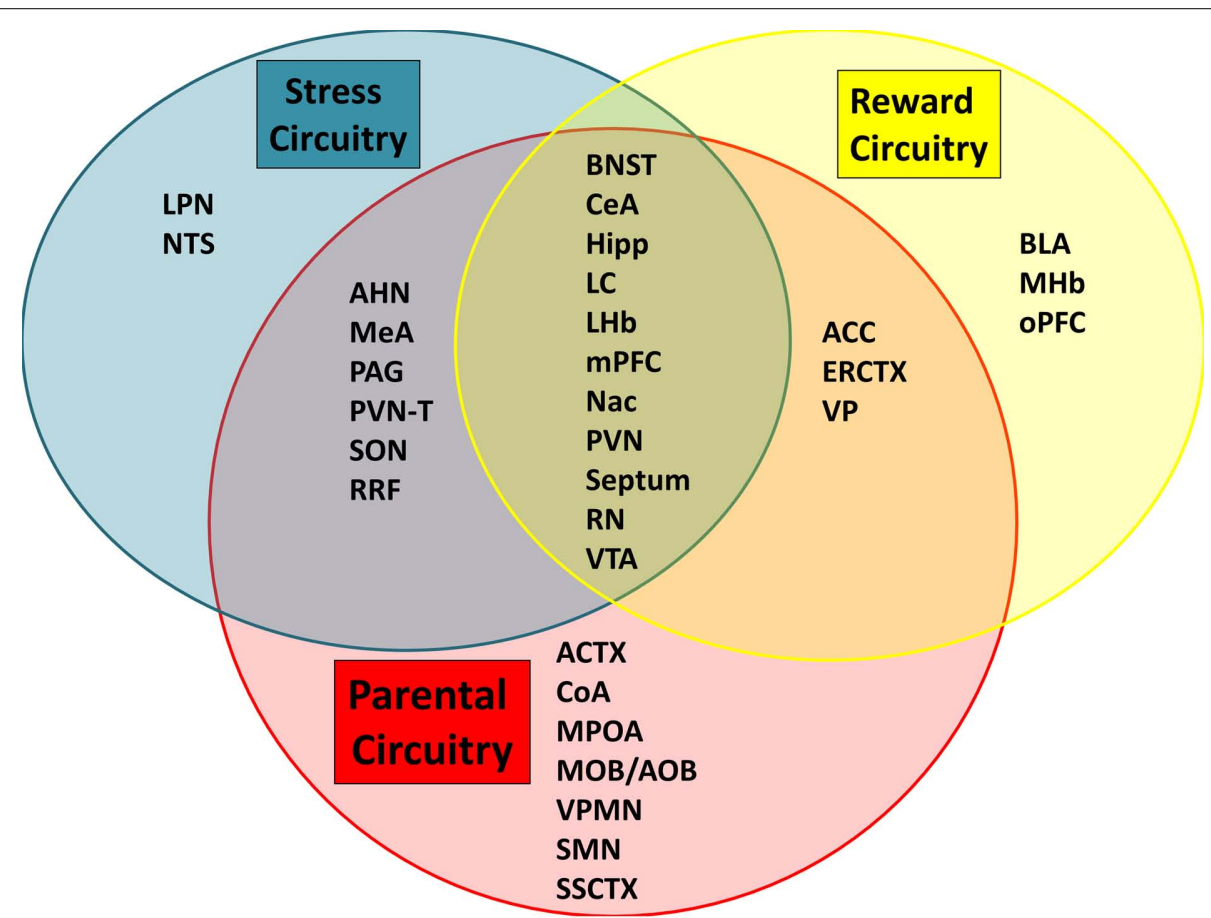

ACC: anterior cingulate cortex

ACTX: auditory cortex

ERCTX: entorhinal cortex

MPFC: medial prefrontal cortex

OPFC: orbito-prefrontal cortex

SSCTX: somatosensory cortex

AOB: accessory olfactory bulb

HIPP: hippocampal formation

LHB: lateral habenula

LS: lateral septum

MHB: medial habenula

MOB: main olfactory bulb

PVN-T: paraventricular nucleus of the thalamus VP: ventral pallidum

BNST: bed nucleus of stria terminalis

CEA: central nucleus of amygdala

NAC: nucleus accumbens
BLA: basolateral amygdala

COA: cortical amygdala

MEA: medial amygdala

$\mathrm{AHN}$ : anterior hypothalamic nucleus

MPOA: medial preoptic area of hypothalamus

PVN: paraventricular nucleus of hypothalamus

SMN: supramammilary body

SON: supraoptic nucleus of hypothalamus

VPMN: ventral premammilary body

PAG: periaquaductal gray

RRF: retrorubial field

VTA: ventral tegmental area

LC : locus coereleus

LPN: lateral parabrachial nucleus

NTS: nucleus tractus solitaris

$\mathrm{RN}$ : raphe nuclei
FIGURE 2 |The relationship between neurocircuits of stress, reward, and parenting. Parenting circuitry (red) shares many regions with stress (blue) and reward (yellow). The regions listed in the center have been implicated in all three circuits, suggesting that disruption in regions of one circuit can have profound impact on the functioning of the other connected circuits. It can be seen by the number of regions included in the Parental Circuitry circle that performance of optimal parental care (and the many types of behavior that fall into this category) requires typical functioning of the majority of the brain. Color coding in the legend indicates the anatomical brain systems in which each region belongs.
$5-\mathrm{HT}$ in mice (Yoshida et al., 2009). Deletion of the $5-\mathrm{HT}_{1 \mathrm{~A}}$ or $1 \mathrm{~B}$ receptor can alter time spent crouching in the nest, pup retrieval, or other measures of nurturing, and can change maternal effects on the behavioral profiles of offspring (van Velzen and Toth, 2010). Modifications of the serotonin transporter (5-HTT) can confer increased susceptibility to the effects of poor maternal nurturing or other environmental stressors, with long-term consequences for resilience to adverse conditions (Bakermans-Kranenburg and van Ijzendoorn, 2008; Kinnally et al., 2009; Heiming and Sachser, 2010). Enhanced serotonergic neurotransmission by OT could have similar efficacy in the regulation of CREB function relevant to response to stress, exposure to cocaine and other drugs, and to
MB. The reciprocal interactions between the OT and 5-HT signaling pathways in the midbrain and hypothalamus may be severely disrupted following drug use and may contribute to deficits in MB.

Both plasma and brain OT can interact with hypothalamicpituitary-adrenal (HPA) axis activity (Uvnas-Moberg et al., 2005; Slattery and Neumann, 2008). This information may have implications for human clinical research, as one study recently reported that human mothers who used cocaine during gestation had reduced plasma OT levels and higher perceived stress (Light et al., 2004). The OT system is disrupted by cocaine in several regions, in parallel with behavioral disruptions of MB (Johns et al., 1997a, 2005). For example, the chronic treatment of rat dams with cocaine 


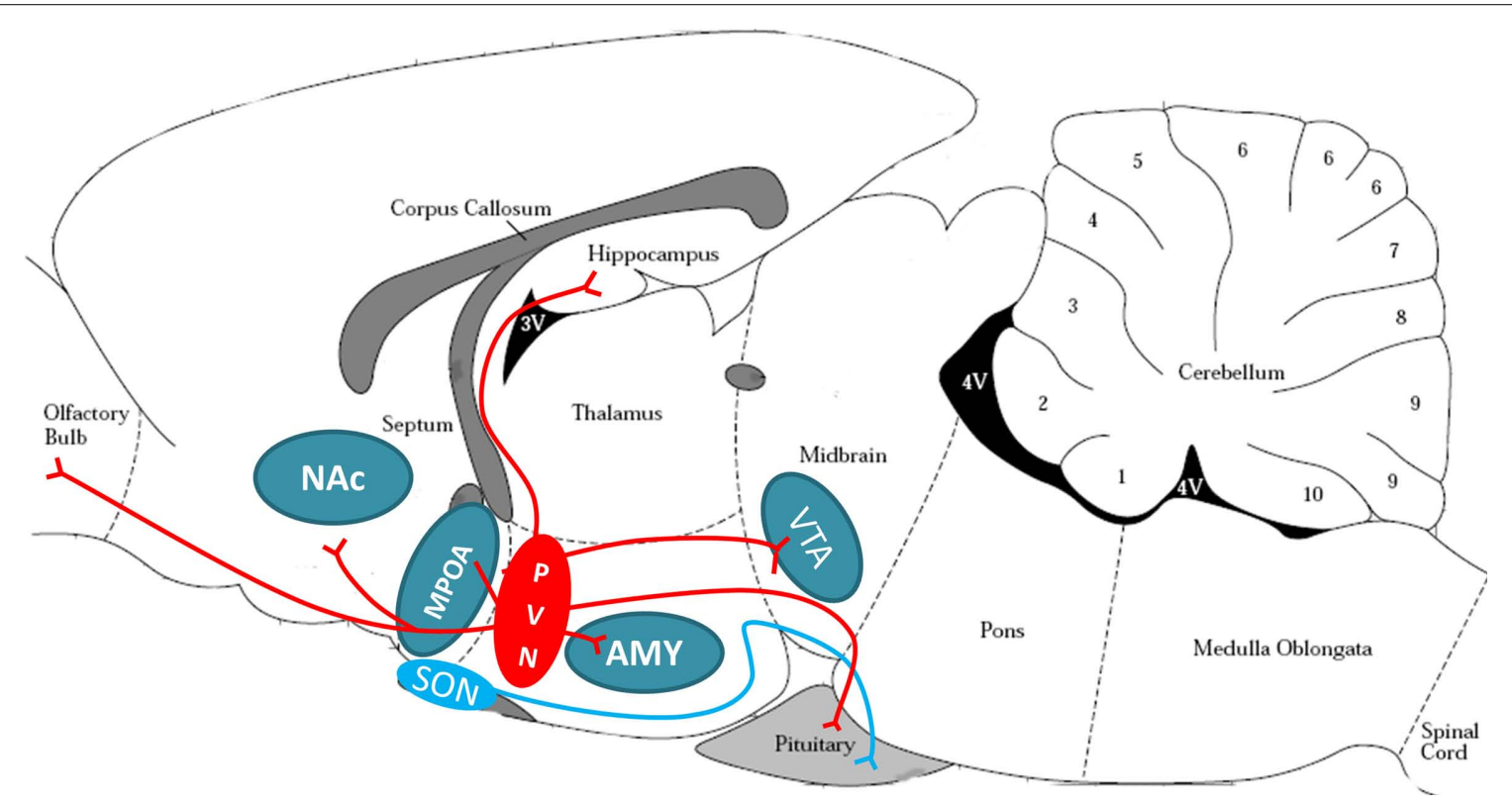

FIGURE 3 | Oxytocinergic projection in the rodent brain. Oxytocin release is anatomically suited to signal in reward, stress, and maternal circuitries. The magnocellular neurons of the PVN (red oval) and SON (blue oval) project to the posterior pituitary to release OT peripherally in response to suckling or stressful stimuli. The parvocellular neurons of the PVN also project to the reward circuitry (VTA and NAc), stress circuitry (hippocampus, AMY, and
intra-PVN release), and maternal circuitry (MPOA/BNST and OB), and are believed to be critical for appropriate social interactions. PVN, paraventricular nucleus of hypothalamus; SON, supraoptic nucleus of hypothalamus; VTA, ventral tegmental area; NAc, nucleus accumbens; AMY, amygdala; MPOA, medial preoptic area of the hypothalamus; OB, olfactory bulb. Brain schematic adapted from Paxinos and Watson (1997). can significantly lower OT levels in the MPOA, hippocampus, and VTA within 24 h of delivery (Johns et al., 1997a). Acute cocaine in the postpartum period can affect OT levels and OT receptors in several brain regions, including lowering levels in the MPOA on postpartum day (PPD) 1, and raising levels in the AMY on PPD 6 (Jarrett et al., 2006; McMurray et al., 2008). Interestingly, OT can also play a role in drug-reward effects. Recent studies in rodent models have shown that OT administration can reduce or block psychostimulant-related responses in tests of conditioned place preference (CPP), self-administration, and reinstatement of drug-seeking behavior (Yang et al., 2010). These data suggest an important role for OT at the intersection of addiction, stress, and $\mathrm{MB}$.

\section{ADAPTION OF THE REWARD SYSTEM FOR PARENTING AND THE IMPACT OF COCAINE}

Pups and pup cues have rewarding (motivational) value to rat dams, shown in both CPP and operant responding paradigms (Lee et al., 2000; Mattson and Morrell, 2005). Of particular note, pups often induce CPP greater than the effect of cocaine, indicating the strength of the motivational salience of pups (Seip and Morrell, 2009). However, in rodent studies, as many as $30 \%$ of dams prefer a non-pup associated chamber, and these dams exhibit greater locomotor sensitization to cocaine, indicating a subset of the population may be more vulnerable to cocaine's impact on reward circuitry and thus impairments in MB (Mattson and Morrell, 2005; Seip and Morrell, 2007). The circuitry controlling incentive value of reinforcing cues seems to be transiently altered postpartum as dams lack aversive responses (as measured by CPP) after receiving subcutaneous cocaine injections compared to virgin female rats, suggesting that internal physiology can play a major role in the conditioning effects of drugs (Seip et al., 2008).

Multiple reviews of reward circuitry have proposed that DA has a prominent role in drug reward and that the "reward circuit," as presented in Figure 4, consists of a midbrain-forebrain pathway that connects the VTA with the NAc and mPFC, with information converging in the NAc to drive locomotor responses toward reward seeking (Koob and Volkow, 2010; Sesack and Grace, 2010). Widespread use of fMRI has also enabled reward circuitry in humans to be investigated, with comparable regions identified, including the orbitofrontal cortex (OFC), amygdala, NAc, as well as the PFC and anterior cingulate cortex (ACC; McClure et al., 2004). A growing literature is emerging that dissects reward-seeking behaviors into independent cognitive processes: "wanting," "liking," and "learning” (Berridge, 2004; Berridge et al., 2009). Liking is defined as the neural reaction underlying sensory pleasure-triggered by immediate receipt of reward. In contrast, "wanting" is defined as the motivational incentive value of the same reward. It has been postulated that dopaminergic signaling described above (VTA/Nac/mPFC) is most important for the "wanting" aspects of behavior. This theory may help explain why, although certain aspects of maternal care are unlikely to have high hedonic impact (i.e., initial nursing, maternal aggression, sleep interruption), mothers still "want" to provide maternal care.

\section{VENTRAL TEGMENTAL AREA}

Ventral tegmental area DA neuron activity is responsible for transient and phasic DA release into the NAc (Sombers et al., 2009) 


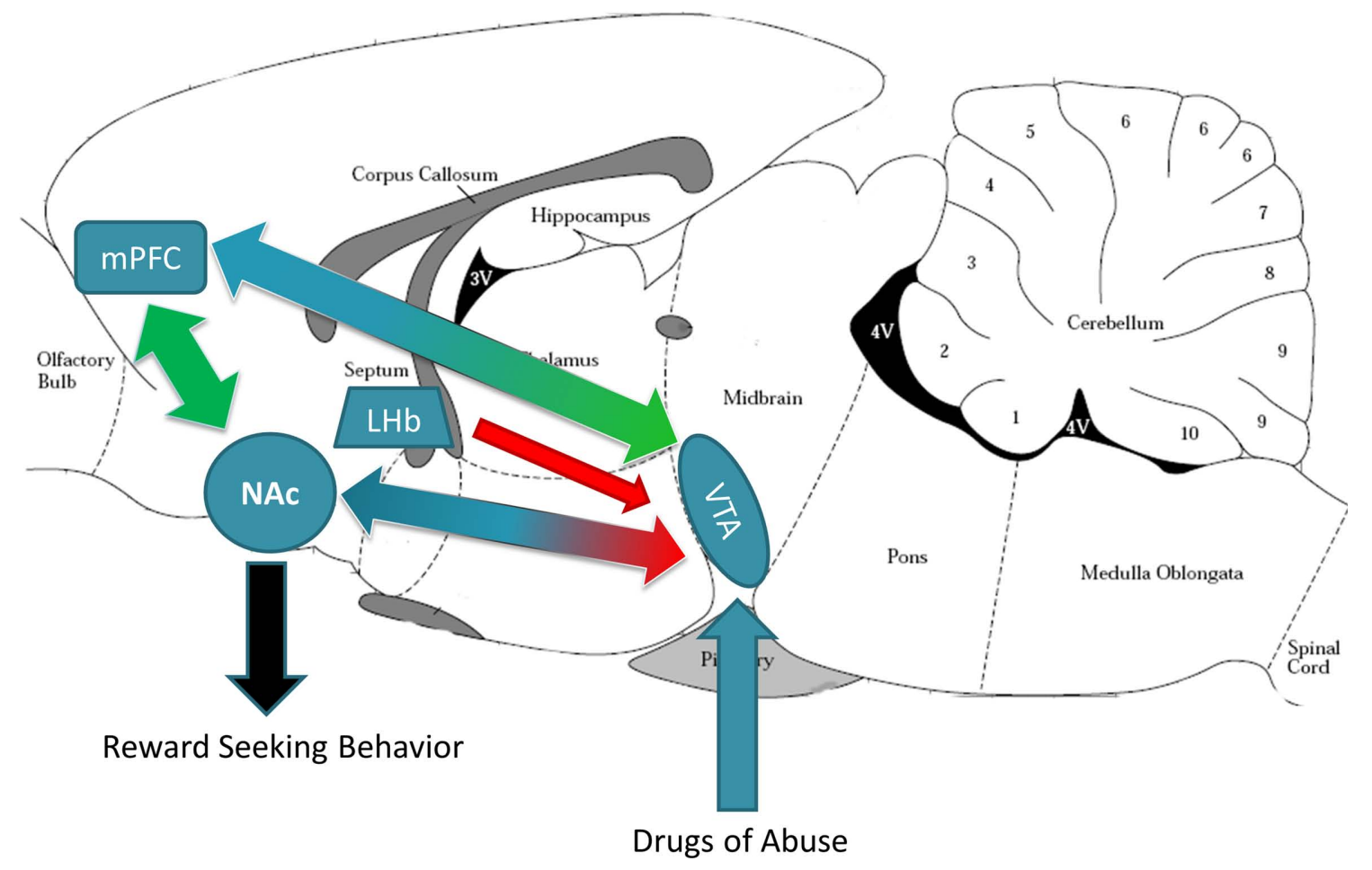

FIGURE 4 | Reward circuitry in the rodent brain. This midline sagittal slice of rodent brain depicts the main brain regions implicated in responding to rewarding stimuli. The ventral tegmental area (VTA) of the midbrain sends dopaminergic projections (blue arrows) to the nucleus accumbens (NAc) and medial prefrontal cortex (mPFC). The NAc (as well as the lateral habenula,
$\mathrm{LHb}$ ) send GABAergic projections (red arrows) to the VTA, while the MPFC sends glutamatergic projections (green arrows) to the VTA. The mPFC and NAc have reciprocal glutamatergic projections. Activity changes in the NAc results in reward seeking or incentive behaviors (black arrow). Brain schematic adapted from Paxinos and Watson (1997). as well as throughout the reward circuitry, and VTA activity is believed to be crucial for incentive valuation and goal-oriented behaviors (Koob and Volkow, 2010). The VTA consists of DA projection neurons, surrounded by GABAergic interneurons (for review Adell and Artigas, 2004). Cocaine exposure impacts VTA function in ways that may alter its ability to respond to naturally rewarding stimuli. Synaptic levels of 5-HT, NE, and DA are acutely increased by cocaine through its ability to block their transporters, resulting in increased firing rates (Thomas and Malenka, 2003). Cocaine also contributes to increased firing by reducing inhibition, via decreased VTA GABAergic interneuron firing (Steffensen et al., 2008). These cocaine-induced changes do not habituate with repeated exposure; thus, cocaine acutely and chronically increases excitatory tone in the VTA, resulting in higher firing rates (Thomas and Malenka, 2003), potentially creating a threshold for firing that new (infant) stimuli cannot reach. Ovarian hormones enhance cocaine's effect on VTA DA firing in female rats (Zhang et al., 2008), suggesting changes may be accentuated during pregnancy when ovarian hormones are highly upregulated. Importantly, cocaine self-administration causes long-lasting potentiation in the VTA that sucrose self-administration does not (Chen et al., 2008), suggesting that cocaine may prevent further plasticity in the VTA that is needed during the postpartum period.

Evidence from rodent studies supports a role for the DA projection neurons from the VTA in the incentive aspects of MB (Numan, 2007). Lesions of the VTA, or that sever axons from the MPOA to the VTA, disrupt MB (Numan, 2007). Transient inactivation of the VTA, especially through $\mathrm{GABA}_{A}$ receptors, disrupts maternal retrieval, nursing, and CPP for pups (Numan et al., 2009; Seip and Morrell, 2009), while not disrupting cocaine CPP, suggesting that VTA activity is critical for responses to pup stimuli. Mice that are naturally neglectful of their pups show higher basal c-FOS activation, although there is no difference in the number of DA cells in the VTA (Gammie et al., 2008a). This suggests that ignoring pups may be perceived as rewarding for these dams, perhaps due to a reduction in stress. However, whether pup removal decreases stress and increases reward signal in some dams but not others has yet to be directly tested. Electroencephalogram (EEG) and fMRI responses in the VTA are increased by exposure to pups and pup olfactory cues (Febo et al., 2005; Hernandez-Gonzalez et al., 2005). Direct application of OT or opioids in the VTA can facilitate MB (Pedersen et al., 1994; Thompson and Kristal, 1996). Recent evidence has indicated a direct role for OT in regulation of VTA DA cell firing and DA release into the forebrain (Shahrokh et al., 2010). Interestingly, OT antagonists reduce DA release in highly maternal dams, but not in low maternal dams, suggesting there may a "floor" effect on the ability of OT to direct DA cell firing. Taken together, these findings indicate disruption in VTA function can severely affect $\mathrm{MB}$ and the rewarding value of pups to dams. Gestational cocaine treatment does not affect basal levels of NE, DA, or DA metabolites in the VTA during the postpartum period; however, basal 5-HT and OT are decreased (Johns et al., 1997a; 
Lubin et al., 2003). These data, along with previously mentioned cocaine-induced changes in VTA function, suggest that VTA neurons may be less responsive to OT and thus fire less, although this has yet to be directly tested.

\section{NUCLEUS ACCUMBENS}

The NAc, divided into the core and shell, serves several behavioral functions. The shell is involved in the incentive motivational properties of rewarding stimuli via the enhancement of stimulusreward associations, while the core is involved in the performance components of reward seeking (Di Chiara, 2002; Russo et al., 2010). In humans, the NAc mediates the anticipation and prediction of reward (Knutson and Cooper, 2005), with regional activity varying dependent upon reward magnitude (Haber and Knutson, 2009). The NAc consists primarily of GABAergic projection neurons and interneurons. The major NAc GABAeric efferents project to the lateral hypothalamus, VTA, substantia nigra, brainstem, and ventral pallidum, whose activity is correlated with reward seeking (Koob and Volkow, 2010). Activation of inhibitory DA transmission from the VTA in the NAc in response to acute administration of all major drugs of abuse has been observed (Koob and Volkow, 2010). Cocaine acutely increases levels of inhibitory 5-HT and NE as well (Li et al., 1996). Chronic cocaine exposure upregulates $D_{1}$ receptors in the striatum (Ben Shahar et al., 2007), similar to expression in highly maternal dams (Champagne et al., 2004), suggesting that repeated exposure to rewarding stimuli may have similar effects. Although DA transporter expression is unchanged, its activity increases with cocaine consumption (Oleson et al., 2009). Chronic cocaine exposure upregulates 5-HT transporter expression, while not impacting NE transporter expression (Belej et al., 1996). Increases in transporter activity may indicate an attempt of the neurons to return to a level of firing similar to that observed prior to drug use. Cocaine exposure decreases synaptic strength between excitatory PFC afferents to the NAc shell, and causes long-lasting decreased firing in the core (Russo et al., 2010).

The NAc is important for the initiation and maintenance of MB. NAc ablation significantly decreases $M B$, and specifically lesioning the NAc shell disrupts retrieval behavior without interrupting crouching, licking, or nest-building (Li and Fleming, 2003). The NAc shows increased neuronal activation, through c-FOS expression and fMRI, in response to pups throughout the first postpartum week (Fleming and Korsmit, 1996; Febo et al., 2005). However, no response is observed only to pup cues (Fleming and Korsmit, 1996). In contrast, activation in response to infant cries (relative to white noise) have been observed in human mothers in the regions surrounding the NAc, as well as more extensive cortical and subcortial regions, primarily innervated by dopamine (Lorberbaum et al., 2002).

Lactating rats have lower basal DA in the NAc compared to virgin rats (Olazabal et al., 2004), perhaps allowing greater sensitivity to changes in levels. Real-time in vivo voltammetry and microdialysis measurements have shown increased NAc shell DA during nursing, and a direct correlation of DA concentration with duration of licking behavior (Champagne et al., 2004; Afonso et al., 2008). Treatment with DA agonists increases licking specifically in dams that were previously characterized as "low-licking"
(Champagne et al., 2004), suggesting that some threshold must be met to achieve higher licking rates. Similar pharmacological treatments in NAc have been shown to mediate "wanting" of rewards (Berridge et al., 2009). Recently, it has been shown that $\mathrm{D}_{2}$ receptor activation is important for normal MB (Zhao and $\mathrm{Li}, 2010)$. Although $\mathrm{D}_{2}$ receptor binding does not differ between dams that are highly maternal and those which are lowlicking/nursing, highly maternal dams have more $\mathrm{D}_{1}$ and $\mathrm{D}_{3}$ receptors and lower DA transporter binding in the NAc shell compared to low-licking/grooming dams (Champagne et al., 2004). In a mouse line bred for maternal neglect, much higher c-FOS expression is observed immediately following the onset of neglect compared to control dams (Gammie et al., 2008a), with the effect greater in the core than the shell. Taken together, dopaminergic signaling in the NAc is critical for $\mathrm{MB}$, and since drug use can drastically alter signaling, this may lead to impaired MB. However, little is known about how drug exposure may impact plasticity within the NAc during pregnancy, parturition, and lactation and this will be a focus of future research.

\section{PREFRONTAL CORTEX}

The PFC is involved in a variety of cognitive functions, all of which are critical components in the shift toward drug dependency, addiction, or MB. Understanding the role of the PFC is complex, especially given the wide variation in the degree of cortical parcellation in both human and animal studies (including ACC, OFC, mPFC, and infralimbic) observed across studies (Dalley et al., 2004). The ACC has been associated with the integration and valuation of social information due to its direct connections with AMY, ventral striatum, hypothalamus, periaqueductal gray (PAG), and auditory cortex (Dalley et al., 2004), as well as ordering temporal sequence of behaviors. The OFC, which has a well-established role in decision-making and stimulus-reward relationships, receives input from all sensory modalities as well as the ventral striatum and amygdala. Damage to the OFC may result in changes in anxiety/fear and aggressive behaviors, suggesting its importance in social interactions. The prelimbic and infralimbic cortices, which are subdivisions of the mPFC residing dorsally and ventrally respectively, have been associated with working memory function and attention. However, they play different roles in learning, with the prelimbic cortex contributing to action-outcome associations and the infralimbic contributing to habit formation in rodents. Both the mPFC and OFC have been implicated in controlling impulsivity (Dalley et al., 2004), a point we will return to later. Given that all these functions are critical for appropriate social interactions, understanding how drug use alters their function will highlight how these regions may be involved in altered postpartum behaviors.

Chronic drug use has been tied to deficits in monoamine signaling in the PFC; however it remains unclear whether these deficits are causative or predictive (reviews: Dalley et al., 2008; Koob and Volkow, 2010; Sesack and Grace, 2010). Recent evidence suggests molecular mechanisms underlying drug-induced dysfunction. Glucose metabolism increases following acute cocaine, but decreases following cocaine self-administration, indicating an adapted neuronal response (Hammer Jr. and Cooke, 1994). Cocaine increases blood flow in fMRI studies involving male, 
female, and lactating rats (Febo et al., 2004; Ferris et al., 2005). This increased "activation" of the mPFC, measured by increased blood flow, may result from increased activity of GABAergic interneurons instead of glutamatergic projection neurons, since cocaine causes a greater VTA-driven inhibition of $\mathrm{mPFC}$ projection neurons (Peterson et al., 1990), suggesting an increased inhibition of projection neurons in this area. Cocaine consumption results in hundreds of synaptic plasticity gene expression changes as measured by microarray (Freeman et al., 2010) as well as an upregulation of $\mathrm{D}_{1}$ receptor and corticotropin releasing factor (CRF) activity (Ben Shahar et al., 2007; Corominas et al., 2010). Taken together, these data suggest multiple mechanisms for a decline in mPFC function through cocaine use. The ACC, OFC, infralimbic, and prelimbic cortex all show increased c-FOS expression in response to cocaine-associated cues compared to saline controls (Ciccocioppo et al., 2001), indicating an important role for drug learning in these areas. Given that these regions are likely responding to cocaine exposure through plastic changes to gene expression, these neurons may not respond with the appropriate amount of neuroplasticity needed for the transition to perform MBs. A single study of cocaine administration prior to pregnancy demonstrated diminished activation to pup suckling in the mPFC, but did not affect baseline DA or percent increase of DA upon exposure to pups in the mPFC (Febo and Ferris, 2007). However, whether cocaine during pregnancy affects the development of plastic changes in the PFC during pregnancy and lactation, similar to those observed in males has yet to be directly tested.

The PFC's role in organizing behavior is critical for the transition to $\mathrm{MB}$, with disruptions to $\mathrm{PFC}$ function resulting in deficits to MB. Pharmacological antagonism of sodium channels or activation of GABA in the mPFC has shown that this region is necessary for retrieval behavior of rat dams (Febo et al., 2010). These experiments did not change approach behavior toward pups, only the decision to retrieve them to the nest, indicating a change in motivation not investigatory behaviors. Excitotoxic lesion to the mPFC also disrupts pup retrieval, licking, and the overall pattern or order of MBs, indicating the importance of this region in working memory and attention in the postpartum period (Afonso et al., 2007). Pup suckling increases fMRI response in the medial and lateral PFC and insular cortex of lactating rats, an effect that is dependent on OT (Febo et al., 2005). EEG data suggest that mPFC activity changes in response to pup odors (Hernandez-Gonzalez et al., 2005). As mentioned above, DA contributes to PFC function. DA levels are lower in rats in late pregnancy compared to virgin female rats (Olazabal et al., 2004), which may result in higher overall activity given that DA acts to inhibit activity in the mPFC (Peterson et al., 1990). Recently, high impulsivity has been tied to deficits in $\mathrm{MB}$, which may be associated with alterations in mPFC function (Lovic et al., 2010). Since mPFC DA is an important mediator of impulsivity (Dalley et al., 2008) and can be disrupted by drug abuse, differences in behavioral organization during MB could occur following drug use (although this has yet to be directly tested). Notably, as early as PPD1, the cingulate cortex shows increased c-FOS expression in response to pups, and continues to respond to cues through the first week (Fleming and Korsmit, 1996). Additionally, the infralimbic cortex responds to cues while the prelimbic cortex does not (Fleming and Korsmit,
1996), suggesting the importance of specific regionalization of circuitry.

In human mothers, although widespread activity in the brain is observed when exposed to infant cues, the OFC is emerging as a core region in parenting circuitry, being reliably engaged across studies as well as in different modalities. Activity in the right OFC was greater when mothers listened to infant cries compared to white noise (Lorberbaum et al., 1999, 2002), and bilateral OFC activity increased when mothers viewed photographs of their own child compared to an unfamiliar child (Nitschke et al., 2004). Bridging brain and self-reported mood, this bilateral activity in the OFC has been significantly correlated with positive mood scores while viewing infant faces (Nitschke et al., 2004), with left OFC activity correlating with positive mood and right OFC activity correlating with negative mood scores in a subsequent study (Noriuchi et al., 2008). In this latter report, other regions showed sensitivity to infant familiarity, including the dorsolateral PFC, insula, putamen, and PAG. In preclinical work, the PAG is thought to mediate the immobile stance of nursing since exposure to suckling pups selectively activates PAG to a greater extent than exposure to non-suckling pups (Lonstein and Stern, 1997). The PAG has also been strongly implicated in controlling aggressive behavior in the postpartum period and mediating fearfulness or anxiety (Lonstein et al., 1998). It is worth noting that the lateral OFC (and PAG) responds selectively to cues of maternal attachment, with overlapping regions including striatum, insula, and dorsal ACC responding to cues of maternal and romantic attachment (Bartels and Zeki, 2004). Magnetoencephalography has also demonstrated the role of the OFC to infant cue sensitivity and further suggests that OFC may exert a top-down role on infant face perception (Kringelbach et al., 2008). In a sample containing both parents and non-parents, $130 \mathrm{~ms}$ post-stimulus onset there was a significant increase in activity in the mOFC in response to viewing infant faces but not adult faces. Moreover, this early sensitivity to infant faces was not observed in areas traditionally associated with face processing (i.e., fusiform cortex). Nevertheless, after $165 \mathrm{~ms}$ from face presentation, a comparable divergence of activity in response to infant and adult faces in fusiform cortex was observed. These findings suggest that the mOFC is not only sensitive to infant cues, but may also modulate subsequent activity in fusiform regions for preferential processing of infant face stimuli.

\section{LATERAL HABENULA}

Another forebrain region that can contribute to the $\mathrm{MB}$ is the lateral habenula (LHb; Geisler and Trimble, 2008). LHb activity is correlated with the lack of an expected reward as well as stressful stimuli, suggesting a role for processing the saliency and value of rewarding and distressing stimuli. The LHb shows increased cFOS to acute cocaine and cocaine-associated cues but this response diminishes following repeated exposure (Franklin and Druhan, 2000), suggesting that cocaine exposure disrupts the ability of the LHb to decrease VTA activity. This may be especially important if VTA neurons have reached a level of firing that cannot change further in response to infant stimuli. This structure is activated in response to pups on PPD7 and reacts to pup cues on PPD 10 (Felton et al., 1998). Interestingly, the c-FOS response is 
diminished in dams that exhibit strong CPP for pups. This may be explained by the role of the LHb in negative reward salience (Mattson and Morrell, 2005). The LHb has also been shown to have both excitatory input and output following MB (Geisler and Trimble, 2008). This is an intriguing area of future research as it may play a critical role in determining the salience of different stimuli during the postpartum.

In summary, a number of core structures have been identified in the reward neural circuitry and we have described the evidence to suggest their adaption to parenting. The modulation of these neurocircuits by cocaine implicates a neurobiological pathway through which substance use can affect parenting behavior. The role of the reward circuitry, specifically mesocorticolimbic DA, has also been implicated in social attachment more broadly in preclinical studies of MB and pair bonding (Insel, 2003). This will be an important avenue for future research to understand how cocaine influences $\mathrm{MB}$ as well as the formation and maintenance of maternal attachment.

\section{ADAPTION OF THE STRESS SYSTEM FOR PARENTING AND THE IMPACT OF COCAINE}

In addition to the reward neural circuits, there is also significant recruitment of stress neurocircuits in $\mathrm{MB}$ across humans and rodents. Moreover, a wealth of behavioral data implicates stress in drug seeking and relapse (Corominas et al., 2010; Koob and Volkow, 2010). Therefore we turn our attention to the neural circuitry of the stress system, its involvement in $\mathrm{MB}$, and modulation by cocaine.

\section{HPA AXIS}

The canonical HPA axis stress system seems to play a critical role in the development of drug abuse, while extrahypothalamic stress circuitry [BNST, hippocampus, medial portion of NAc, and central amydala $(\mathrm{CeA})]$ appears to have a more important role in the motivational effects of both acute withdrawal and stress-induced relapse (Aston-Jones and Harris, 2004; Corominas et al., 2010; Koob and Volkow, 2010). It has been hypothesized that addiction results from a neuroadaptational shift in how rewards are processed, specifically a loss of positive reinforcement and replacement by negative reinforcement within a basal circuit termed the extended amygdala (Koob and Volkow, 2010). This long-lasting shift in how the brain stress systems process similar environmental cues (allostasis) following either drug exposure or repeated stressful events has been defined as allostatic load (McEwen and Gianaros, 2011). Alterations in allostatic load are derived by chronic exposure to psychological or physiological stressors.

Acutely, the HPA axis is activated by a variety of external and internal events (see Figure 5). The PVN in the hypothalamus

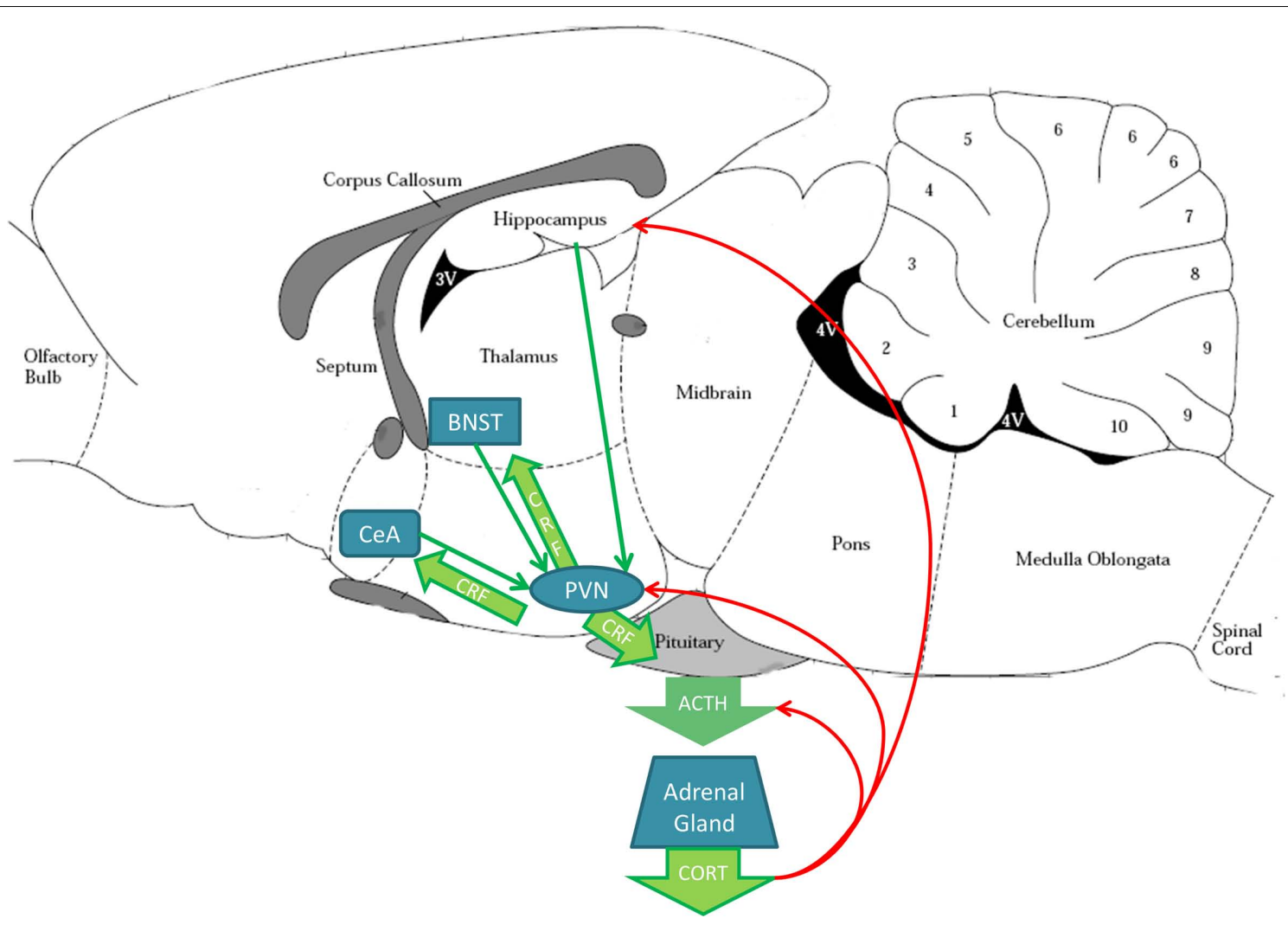

FIGURE 5 | Stress circuitry in the rodent brain. The paraventricular nucleus (PVN) in the hypothalamus sends corticotrophin releasing factor (CRF) projections (green arrows) to the central amygdala ( $\mathrm{CeA}$ ), bed nucleus of the stria terminalis (BNST), and the pituitary gland. The pituitary gland releases adrenocorticotrophic hormone (ACTH) into the blood stream that travels to the adrenal gland. Adrenal gland releases corticosterone (CORT) into the bloodstream. CORT acts as a negative feedback signal (red arrows) on the pituitary, PVN, and hippocampus, which sends excitatory projections to the PVN (green line arrows). The PVN receives additional excitatory input from the CeA and BNST. Brain schematic adapted from Paxinos and Watson (1997). 
releases CRF into the hypophyseal blood supply, stimulating release of adrenocorticotropic hormone (ACTH) from the pituitary gland into the circulating blood supply. ACTH acts on the adrenal medulla to release glucocorticoids (GC), i.e., cortisol (humans) or corticosterone (CORT; rodents) into circulation where it exerts numerous physiological effects. Importantly, CORT exerts negative feedback through GC activation in the pituitary, PVN, and hippocampus, returning the system to homeostasis. In addition to release of CRF into the blood, PVN neurons project to other central nervous system sites, such as the BNST, CeA, and VTA (Palkovits et al., 1998; Rodaros et al., 2007), resulting in a variety of neuronal responses in those brain regions (for review see Corominas et al., 2010). The PVN reversibly remodels structurally during pregnancy and lactation to allow greater excitatory input (Panatier and Oliet, 2006), which suggests this is an especially dynamic time for changes in brain stress systems. If drug use alters PVN responsiveness during the postpartum period, this could have deleterious effects given that the PVN also contains cells that produce OT (Slattery and Neumann, 2008), and the PVN has been found to activate in response to pups by PPD7 (Fleming and Korsmit, 1996; Febo et al., 2005).

There is an established bidirectional relationship between substance abuse and stress-related symptomatology in both humans and animal models (Sinha, 2001; Goeders, 2002; Koob and Volkow, 2010). Cocaine acutely activates the HPA axis (Goeders, 2002), a response that is upregulated by female sex hormones (Russo et al., 2003), suggesting that pregnancy, and the accompanying high circulating female steroid hormones, may be an especially sensitive period for cocaine-induced stress hormone effects. Chronic effects depend on the treatment regime; for example, HPA responses neither habituate nor sensitize to daily cocaine administration, although ACTH and CORT responses to binge doses do habituate over repeated exposures (Goeders, 2002). However, selfadministration of cocaine causes an increased CORT response and decreased negative feedback that coincides with lower GC receptors in the PVN but not other forebrain regions (Rodaros et al., 2007), indicating other brain centers can exhibit continued response. HPA reactivity is heightened during acute withdrawal and dysregulation persists during protracted abstinence (Goeders, 2002; Corominas et al., 2010). Importantly, chronic cocaine can raise CORT levels significantly during pregnancy (Quinones-Jenab et al., 2000), although the impact on feedback regulation is less clear. Complementary data has shown that stress and HPA signaling can facilitate psychostimulant self-administration (Goeders, 2002), indicating a mechanism that stress may influence later drug seeking in the postpartum.

The role of the HPA stress system in MB is just beginning to be understood, and it is clear that tight regulation is involved throughout the transition from pregnancy, lactation, and weaning. As mentioned above, allostasis or the dynamic response of the HPA and brain stress systems to ever-changing environments, probably plays a critical role, however, the role of allostatic mechanisms are in great need of study. Gestational and postpartum periods are characterized by high basal CORT levels, a hyporesponsive hormonal reaction to stress, and low anxiety levels (Slattery and Neumann, 2008). Changes in maternal stress responses have been correlated with deficits in maternal care (Smith et al., 2004;
Bosch et al., 2007; Chen et al., 2010). Stress during pregnancy can reduce $\mathrm{MB}$ in rodents, however, if the rats were prone to have low $\mathrm{MB}$, stress did not affect them, suggesting that optimal care can be reduced only to a certain extent (Champagne and Meaney, 2006). Administering CORT to pregnant or lactating rats decreases nursing and increases neglectful behaviors (Bosch et al., 2007; Brummelte and Galea, 2010). Repeated stressors during the postpartum period can inhibit lactation in rodents, suggesting direct hormonal effects (Lau and Simpson, 2004). Conversely, removing circulating stress hormones reduces but does not abolish MB (Rees et al., 2004). Lactation depends on peripheral OT levels and OT is known to bi-directionally interact with HPA activity, with chronic OT treatment leading to reduced acute stress responses (Uvnas-Moberg et al., 2005), suggesting that OT may help mediate stress hyporesponsiveness in the postpartum period (Slattery and Neumann, 2008).

Many neurotransmitters involved in stress regulation are altered in the early postpartum period, including 5-HT, DA, NE, vasopressin, OT, and CRF (Slattery and Neumann, 2008). These signals act primarily within the PVN to direct stress response, especially CRF and OT release. CRF serves as a "stress" signal not only by activating the HPA axis, but also through signaling to the extended amygdala and VTA, resulting in increased saliency of cues surrounding a stressful event (Gulpinar and Yegen, 2004; Corominas et al., 2010). It has been proposed that postpartum changes in stress responsiveness are caused by the reduction in CRF production in the PVN (Slattery and Neumann, 2008), presumably through high OT levels, which can attenuate upregulation of CRF mRNA in response to stress (Lightman et al., 2001; Windle et al., 2004). In a series of studies using mutant mouse lines, Gammie and colleagues have shown that CRF signaling modulates components of MB (Gammie et al., 2007, 2008b; D'Anna and Gammie, 2009). Targeted disruption of CRFR1 significantly reduced nursing, while CRFR2 knockout dams exhibit reduced maternal aggression in a resident-intruder test. Since exposure to an unfamiliar intruder could be highly stressful for a dam, it is possible that CRF function is especially important for $\mathrm{MB}$ related to adverse or anxiogenic conditions. Alterations in CRF-mediated signaling, as observed with repeated cocaine treatment (Corominas et al., 2010), could thus disrupt normal offspring defense. We will now consider the key neural regions which are involved in the stress response, addiction, and parenting; specifically the hippocampus and extended amygdala, before reviewing the important interaction between stress and reward circuitries.

\section{HIPPOCAMPUS}

Hippocampal activity exerts an inhibitory influence, via ventral hippocampal neurons' direct connections to the PVN, and regulates release of stress hormones (Herman et al., 2005). The hippocampus has reciprocal excitatory connections, via the entorhinal cortex, with the mPFC, ACC, insular, and other association cortices, suggesting its role in coordinating spatial and social information, as well as contributing to the stress response during pregnancy and lactation. Chronic cocaine exposure alters monoamine signaling as well as several kinase signaling pathways (Dworkin et al., 1995; Freeman et al., 2001), suggesting cocaine 
may down-regulate the hippocampal formation's ability to temper PVN stress responsiveness.

The hippocampus exhibits increased BOLD signal in response to pup suckling (Febo et al., 2005), and lesions of this area will specifically disrupt MB (Kimble et al., 1967), suggesting perhaps a role for learning safe locations for nursing. The entorhinal cortex, directly adjacent to the hippocampus exhibits the positive BOLD response to pup suckling (Febo et al., 2005), indicating an involvement of social memory. Adult neurogenesis in the hippocampus is decreased in maternally sensitized rats, an effect tied to increased circulating CORT levels (Pawluski and Galea, 2007), and is similar to what is observed following cocaine use (Venkatesan et al., 2007), suggesting that increased CORT from cocaine exposure may decrease neurogenesis even further, although this remains to be tested. Hippocampal monoamine levels do not change throughout pregnancy or following gestational cocaine exposure (Lubin et al., 2003; Olazabal et al., 2004), indicating that potential changes in function may rely on CRF and CORT signaling. In addition, OT levels are decreased in the hippocampus in virgin rats and in the postpartum following chronic gestational cocaine exposure (Johns et al., 1997a; Lubin et al., 2001), which may suggest as interaction with CRF and CORT.

\section{EXTENDED AMYGDALA}

The extended amygdala contributes to processing emotions (particularly fear and anxiety), refining the limbic input to motor systems (Alheid, 2003; Koob and Volkow, 2010) and may be involved in the integration of cortical information with the HPA axis function. The extended amygdala consists of the CeA, medial amygdala (MeA), sublenticular extended amygdala, BNST, and medial and caudal portions of the NAc (Alheid, 2003). The CeA and BNST have reciprocal connections with the PVN and are an independent source of CRF (Alheid, 2003). Cocaine exposure results in longterm changes in CRF activity in these regions (Corominas et al., 2010). Chronic cocaine treatment has short and long-term effects on the neuronal response to stress by increasing CRF-dependent activation in the amygdala and BNST in response to stress in males (Kash et al., 2008); however, its effects on females are less clear. Signaling mediated by CRF has been implicated in neuroadaptation during a chronic cocaine regimen and reinstatement of cocaine reward (Corominas et al., 2010). Although a majority of this work has focused on withdrawal from cocaine, it suggests that the chronic exposure alters CRF signaling. Additionally, the conditioned release of NE, which may be altered by cocaine exposure, in the BNST in response to stressors may elevate anxiety which then augments the reward value of drugs through negative reinforcement (Aston-Jones and Harris, 2004; Koob and Volkow, 2010). Overall, these lines of evidence support a role for this region as a critical convergence point between reward and stress circuitry in addiction. Acute cocaine can increase OT in the amygdala (Elliott et al., 2001), while chronic cocaine treatment during pregnancy reduces OT receptor binding in the BNST and amygdala in the early postpartum (Johns et al., 2004; Jarrett et al., 2006).

Disruptions in extended amygdala activity can have major detrimental effects on MB. Activation of the amygdala and BNST regions can lead to decreases in $\mathrm{MB}$ (Rasia-Filho et al., 2000; Walker et al., 2003; Bosch et al., 2005). In particular, activation of the MeA can inhibit dams from approaching pups. Further, mouse dams characterized by maternal neglect have higher c-FOS expression in the MeA and CeA compared to control dams (Numan, 2007; Gammie et al., 2008a). The MeA and cortical amygdala (CeA) are activated by exposure to pups during the first week postpartum, but not by exposure to pup cues (Fleming et al., 1994a; Fleming and Walsh, 1994b; Stack et al., 2002). The basolateral amygdala (BLA) is not activated until PPD3 and responds to cues on PPD10, consistent with its role in cue-learning (Pego et al., 2008). OT in the AMY is important for regulating anxiety and maternal aggressive behavior, and is increased following chronic cocaine exposure (Bosch et al., 2005; McMurray et al., 2008). Given the complex changes occurring in the extended amygdala during the postpartum, it is likely that previous drug use may interrupt the normal course of functional plasticity.

\section{THE INTERACTION OF STRESS AND REWARD CIRCUITS}

Importantly, stress alters the reward circuitry. Although the emphasis of stress on reward circuitry function has focused on CRF signaling in the extended amygdala, GC activation is important as well. Chronic stress increases glutamatergic signaling and synaptic function in the NAc shell and the VTA similar to what is observed following psychostimulant exposure (Meshul et al., 1998; Campioni et al., 2009; Lodge and Grace, 2005). Cocaine-induced changes in VTA activity and NAc DA release are dependent on both CRF and CORT (Cleck et al., 2008; Kash et al., 2008). GCs can modulate sensitivity to DA in NAc neurons, especially in lactating rats (Der-Avakian et al., 2006; Byrnes et al., 2007). The role of GCs in sensitizing the NAc to psychostimulants may be especially important, given the large amount of circulating GC during pregnancy and lactation (Byrnes et al., 2007). The transcription factor CREB has been implicated in persistent changes in the brain following exposure to drugs of addiction or stressful environmental events, and is expressed throughout the reward circuitry (Briand and Blendy, 2010). Increased levels of phosphorylated CREB may be an important mechanism in the acute and chronic effects of cocaine administration and sensitization (Briand and Blendy, 2010), and in stress-induced reinstatement of conditioned responses to cocaine (Kreibich and Blendy, 2004). Disruption of $C R E B$ function can lead to higher sensitivity to the rewarding effects of cocaine, but disrupts potentiation of drugrelated behavior following episodes of stress (Dinieri et al., 2009), while CREB overexpression can attenuate locomotor effects of cocaine (Kreibich et al., 2009; Briand and Blendy, 2010). Disruption of signaling through CRF receptor 1 can block stress-induced enhancement of conditioned responses to cocaine, as well as stresselicited increases in phosphorylated CREB (Kreibich et al., 2009). Taken together, these data suggest that cocaine-induced changes in stress signaling may interact synergistically with changes in the reward circuitry to affect maternal response.

Finally it is important to note the proposal that the maintenance of allostatic processes requires the coordinated signaling between the hippocampus, amygdala, and PFC (McEwen and Gianaros, 2011). Since it is clear that these regions are important for reaction to stress and initiation and maintenance of $\mathrm{MB}$, and are negatively impacted by cocaine exposure, they highlight regions that deserve further research in drug-exposed parenting models. 


\section{PARENTING CUES AS STRESSFUL CUES IN ADDICTION}

As we have reviewed here, the neural circuitry of the reward and stress systems contribute to substance use initiation, as well as continued use and subsequent dependence. Many of the key neural structures within these circuits are also those that are observed in studies of parenting, suggesting that these overlapping neural circuits present as mechanisms through which drugs of abuse can modulate parenting behavior. These findings related to the model presented in the introduction to this review are presented in Figure 6. The final component of our model posits that in the addicted situation, infant cues are stressful rather than rewarding, and that heightened levels of stress increases craving for substances of abuse that through past experience have been associated with the relief of negative affect. Therefore, the act of caring for an infant may promote drug-seeking behaviors in currently using mothers, as well as triggering relapse in abstinent mothers.

At a neurobiological level, the relationship between parenting, addiction, and stress is in its infancy. However, substance use has been well associated with stress-related symptomatology (Sinha, 2001), and early on stress has been highlighted as modulating parenting behavior (Webster-Stratton, 1990). Increasing levels of stress in parenting are believed to be related to insufficient resources (e.g., income, emotional stability) to manage the demands of caring for a child, and that this is enhanced in addicted mothers, who report higher levels of stress than non-substance using mothers (Kelley, 1998). This data suggests that addicted mothers may exhibit a maladaptive shift in allostasic control of stress during the postpartum period. Additional research has evidenced parenting stress as an important mediator to maternal risk factors and their impact on parenting behavior (Suchman and Luthar, 2001). These initial studies support the notion of parenting as a stressor, and we will now consider the relationship between stress and craving which is integral to our model.

Accumulating evidence has shown that individuals with more intense craving when exposed to stress are more likely to relapse, and that drug use affords one means of stress regulation, albeit a maladaptive, self-perpetuating one (Sinha and Li, 2007). In these studies, participants are exposed to an interpersonal stressor and changes in the hemodynamic response are then compared to exposure to a neutral non-stressor condition. In non-substance using individuals, exposure to stress has been shown to increase the hemodynamic response in (1) frontal regions, including the right mPFC and ventral ACC; and (2) limbic and midbrain regions, including the posterior cingulate, left striatum, thalamus, bilateral caudate and putamen, and left hippocampal and parahippocampal regions (Sinha et al., 2004). Further work by the same research group (Sinha et al., 2005) demonstrated that while some changes in the hemodynamic response are common in normal individuals and cocaine-dependent subjects, healthy controls show increased activity in the ACC, while cocaine-dependent participants instead have a decrease in activity in this same region that extended into the lateral frontal cortex. The authors interpret this difference in ACC functioning in relation to differences in emotion regulation and cognitive control between the two groups and the relationship of these functions to addictive behaviors. Replicating their earlier finding, stress exposure increased activity in hippocampal

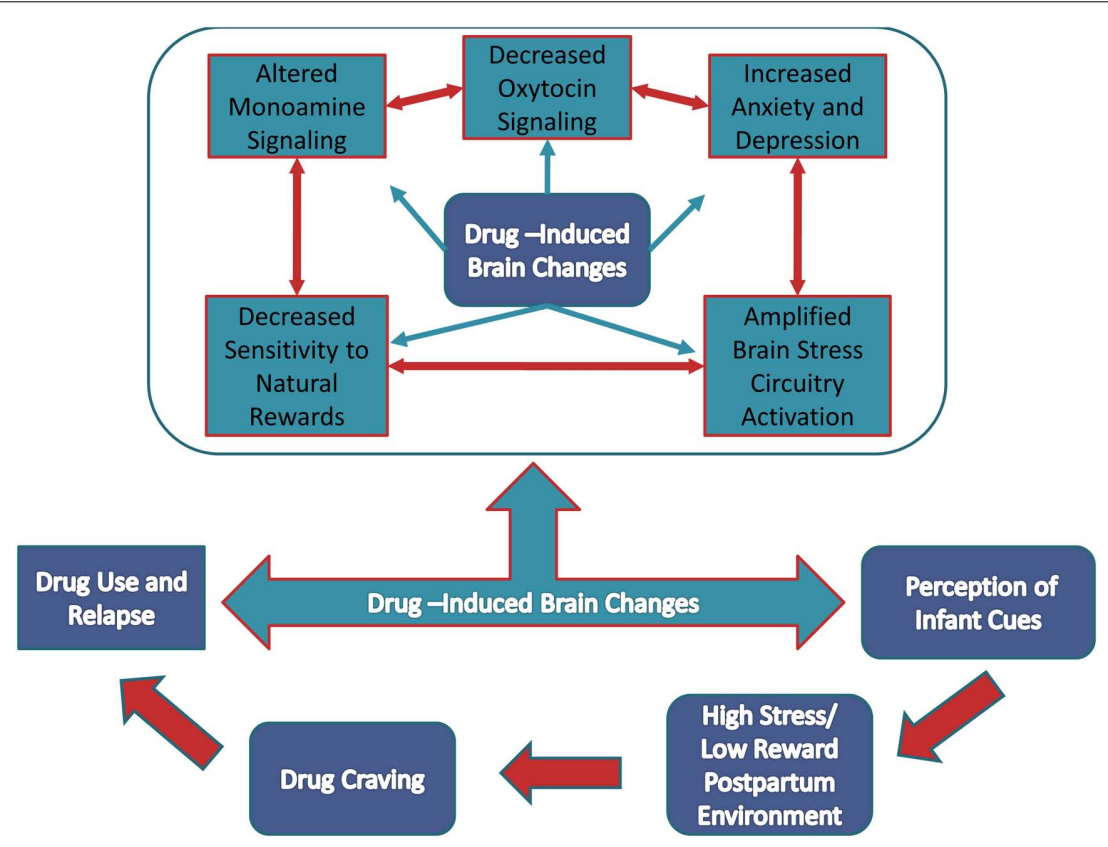

FIGURE 6 | Role of brain changes in the relationship between drug use and parenting. Drug use is known to cause a number of brain changes (teal boxes and arrows). These changes can influence each other (red double-tipped arrows) by either amplifying or diminishing alterations depending on the behavioral and biological context. Importantly, these changes have independently been shown to contribute to parental care behaviors and when disrupted by drug use, results in reduced sensitivity to the rewarding value of infants and heightened stress. The stress response may be sufficient to trigger drug craving leading to continued drug use and relapse in abstinent mothers. In addition, drug seeking to reduce stress may also perpetuate the cycle of neglect. 
and parahippocampal regions in healthy controls, but this response was absent in cocaine-dependent participants, who instead showed an increased response in the bilateral dorsal striatum and caudate region. Activity in this latter region positively correlated with self-report craving scores, consistent with this structure's role in addiction. Increasing activity in the right dorsolateral PFC, as well as the left posterior insular and superior temporal sulcus, also correlated with increasing scores on selfreport of craving and distress in cocaine-dependent participants. The implications of these findings are that, while addiction modulates the stress response, this modulation of activity correlates with self-reports of drug craving, suggesting a putative link between craving, stress, and addiction. This is further emphasized by finding that increasing activity in regions including the medial PFC, following stress induction, predicts time to relapse, correlating with amount of drug use on each occasion, as well as the number of days drug use has occurred following relapse (Sinha and Li, 2007). A wealth of literature, too large to detail here, has begun to discover the molecular mechanisms and brain activation patterns of similar stress-induced relapse behaviors in animal models. Important to our hypotheses are data suggesting that DA and CRF are critical signaling molecules in the VTA, extended amygdala, and PFC (Erb, 2010; Van den Oever et al., 2010; Wise and Morales, 2010), as well as being associated with alterations in allostatic load.

Finding both that exposure to stress results in brain responses that can differentiate addicted individuals from non-addicted individuals and that neural activity correlates with craving and relapse indicate the importance of vulnerability to stress in the maintenance of addiction. Specifically, these studies indicate that exposure to stress heightens craving which results in drug-seeking behavior and relapse. Bridging these results to the present review, we propose that parenting cues will elicit similar stress reactivity (e.g., Kelley, 1998) which could induce drug-seeking behaviors in the addicted mother, thereby likely contributing to neglectful behavior which is so highly correlated with drug addiction in mothers (e.g., Cash and Wilke, 2003). It is the goal of our ongoing preclinical and human subject studies to explore this empirically.

\section{REFERENCES}

Adell, A., and Artigas, F. (2004). The somatodendritic release of dopamine in the ventral tegmental area and its regulation by afferent transmitter systems. Neurosci. Biobehav. Rev. 28, 415-431.

Afonso, V. M., Grella, S. L., Chatterjee, D., and Fleming, A. S. (2008). Previous maternal experience affects accumbal dopaminergic responses to pup-stimuli. Brain Res. 1198, 115-123.

Afonso, V. M., Sison, M., Lovic, V., and Fleming, A. S. (2007). Medial prefrontal cortex lesions in the female rat affect sexual and maternal behavior and their sequential organization. Behav. Neurosci. 121, 515-526.

Alheid, G. F. (2003). Extended amygdala and basal forebrain. Ann. N. Y. Acad. Sci. 985, 185-205.
Aston-Jones, G., and Harris, G. C. (2004). Brain substrates for increased drug seeking during protracted withdrawal. $\mathrm{Neu}$ ropharmacology 47(Suppl. 1), 167-179. Ijzendoorn, M. H. (2008). Oxytocin receptor (OXTR) and serotonin transporter (5-HTT) genes associated with observed parenting. Soc. Cogn. Affect. Neurosci. 3, 128-134.

Ball, S. A., Mayes, L. C., DeTeso, J. A., and Schottenfeld, R. S. (1997). Maternal attentiveness of cocaine abusers during child-based assessments. Am. J. Addict. 6, 135-143.

Bartels, A., and Zeki, S. (2004). The neural correlates of maternal and romantic love. Neuroimage 21, 1155-1166.
Bakermans-Kranenburg, M. J., and van

\section{CONCLUSION}

In the review presented here we have identified the contribution of reward and stress pathways to the neural circuitry of parenting, underscoring the modulation of these pathways by addiction. We have described addiction as the dysregulation of the reward and stress systems, the same systems that are adapted for parenting to increase the saliency of infant cues. We propose that in the addictive situation, parenting cues are not as rewarding as they would normally be and could instead be stressful, which with a probable dysregulation of stress adaptation mechanisms, may lead to increased drug seeking and neglectful parenting behavior. While we focused more specifically on cocaine addiction, the principles of this model will likely hold for other addictive processes, owing to the common roles of stress and reward systems in the initiation and maintenance of substance use. Moreover, recognizing early mother-child relationships as a source of stress will be important when considering appropriate therapeutic approaches for prevention as well as treatment of maternal substance abuse (e.g., Pajulo et al., 2006; Suchman et al., 2008). This is emphasized by high relapse rates early postpartum by mothers abstaining from substances of abuse during pregnancy, supporting the notion that the postpartum period presents as a specific time of vulnerability to stress in recent mothers. Indeed, the discussion presented here suggests that therapeutic approaches that target stress regulation may be important for the capacity to parent, maintaining abstinence in addiction, and decreasing the incidence of child abuse and neglect. Potential neurobiological targets could include CRF and OT as they have been shown to be key signaling systems for stress, addiction, and parenting.

\section{ACKNOWLEDGMENTS}

The authors were supported by Award Number P01DA022446 (Josephine M. Johns) from the National Institute on Drug Abuse. The content is solely the responsibility of the authors and does not necessarily represent the official views of the National Institute on Drug Abuse or the National Institutes of Health.

Belej, T., Manji, D., Sioutis, S., Barros, H. M., and Nobrega, J. N. (1996). Changes in serotonin and norepinephrine uptake sites after chronic cocaine: pre- vs. post-withdrawal effects. Brain Res. 736, 287-296.

Ben Shahar, O., Keeley, P., Cook, M., Brake, W., Joyce, M., Nyffeler, M. Heston, R., and Ettenberg, A. (2007). Changes in levels of D1, D2, or NMDA receptors during withdrawal from brief or extended daily access to IV cocaine. Brain Res. 1131, 220-228.

Berridge, K. C. (2004). Motivation concepts in behavioral neuroscience. Physiol. Behav. 81, 179-209.

Berridge, K. C., Robinson, T. E., and Aldridge, J. W. (2009). Dissecting components of reward: 'liking', 'wanting', and learning. Curr. Opin. Pharmacol. 9, 65-73.
Blackwell, P., Kirkhart, K., Schmitt, D., and Kaiser, M. (1998). Cocaine/polydrug-affected dyads: implications for infant cognitive development and mother-infant interaction during the first six postnatal months. J. Appl. Dev. Psychol. 19, 235-248.

Bosch, O. J., Meddle, S. L., Beiderbeck, D. I., Douglas, A. J., and Neumann, I. D. (2005). Brain oxytocin correlates with maternal aggression: link to anxiety. J. Neurosci. 25, 6807-6815.

Bosch, O. J., Musch, W., Bredewold, R., Slattery, D. A., and Neumann, I. D. (2007). Prenatal stress increases HPA axis activity and impairs maternal care in lactating female offspring: implications for postpartum mood disorder. Psychoneuroendocrinology 32, 267-278. 
Briand, L. A., and Blendy, J. A. (2010). Molecular and genetic substrates linking stress and addiction. Brain Res. 1314, 219-234.

Brummelte, S., and Galea, L. A. (2010). Chronic corticosterone during pregnancy and postpartum affects maternal care, cell proliferation and depressive-like behavior in the dam. Horm. Behav. 58, 769-779.

Burns, K., Chethik, L., Burns, W. J., and Clark, R. (1991). Dyadic disturbances in cocaine-abusing mothers and their infants. J. Clin. Psychol. 47, 316-319.

Burns, K. A., Chethik, L., Burns, W. J., and Clark, R. (1997). The early relationship of drug abusing mothers and their infants: an assessment at eight to twelve months of age. J. Clin. Psychol. 53, 279-287.

Byrnes, E. M., Bridges, R. S., Scanlan, V. F., Babb, J. A., and Byrnes, J. J. (2007). Sensorimotor gating and dopamine function in postpartum rats. Neuropsychopharmacology 32, 1021-1031.

Campioni, M. R., Xu, M., and McGehee, D. S. (2009). Stress-induced changes in nucleus accumbens glutamate synaptic plasticity. J. Neurophysiol. 101, 3192-3198.

Cash, S. J., and Wilke, D. J. (2003). An ecological model of maternal substance abuse and child neglect: issues, analyses, and recommendations. Am. J. Orthopsychiatry 73, 392-404.

Champagne, F. A., Chretien, P., Stevenson, C. W., Zhang, T. Y., Gratton, A., and Meaney, M. J. (2004). Variations in nucleus accumbens dopamine associated with individual differences in maternal behavior in the rat. J. Neurosci. 24, 4113-4123.

Champagne, F. A., Curley, J. P., Swaney, W. T., Hasen, N. S., and Keverne, E. B. (2009). Paternal influence on female behavior: the role of Peg3 in exploration, olfaction, and neuroendocrine regulation of maternal behavior of female mice. Behav. Neurosci. 123, 469-480.

Champagne, F. A., and Meaney, M. J. (2006). Stress during gestation alters postpartum maternal care and the development of the offspring in a rodent model. Biol. Psychiatry 59, 1227-1235.

Chen, B. T., Bowers, M. S., Martin, M., Hopf, F. W., Guillory, A. M., Carelli, R. M., Chou, J. K., and Bonci, A. (2008). Cocaine but not natural reward self-administration nor passive cocaine infusion produces persistent LTP in the VTA. Neuron 59, 288-297.
Chen, Y., Holzman, C., Chung, H., Senagore, P., Talge, N. M., and SilerKhodr, T. (2010). Levels of maternal serum corticotropin-releasing hormone $(\mathrm{CRH})$ at midpregnancy in relation to maternal characteristics. Psychoneuroendocrinology 35, 820-832.

Ciccocioppo, R., Sanna, P. P., and Weiss, F. (2001). Cocaine-predictive stimulus induces drug-seeking behavior and neural activation in limbic brain regions after multiple months of abstinence: reversal by $\mathrm{D}(1)$ antagonists. Proc. Natl. Acad. Sci. U.S.A. 98, 1976-1981.

Cleck, J. N., Ecke, L. E., and Blendy, J. A. (2008). Endocrine and gene expression changes following forced swim stress exposure during cocaine abstinence in mice. Psychopharmacology (Berl.) 201, 15-28.

Corominas, M., Roncero, C., and Casas, M. (2010). Corticotropin releasing factor and neuroplasticity in cocaine addiction. Life Sci. 86, 1-9.

Dalley, J. W., Cardinal, R. N., and Robbins, T. W. (2004). Prefrontal executive and cognitive functions in rodents: neural and neurochemical substrates. Neurosci. Biobehav. Rev. 28, 771-784.

Dalley, J. W., Mar, A. C., Economidou, D., and Robbins, T. W. (2008). Neurobehavioral mechanisms of impulsivity: fronto-striatal systems and functional neurochemistry. Pharmacol. Biochem. Behav. 90, 250-260.

D'Anna, K. L., and Gammie, S. C. (2009). Activation of corticotropinreleasing factor receptor 2 in lateral septum negatively regulates maternal defense. Behav. Neurosci. 123, 356-368.

Der-Avakian, A., Bland, S. T., Schmid, M. J., Watkins, L. R., Spencer, R. L., and Maier, S. F. (2006). The role of glucocorticoids in the uncontrollable stress-induced potentiation of nucleus accumbens shell dopamine and conditioned place preference responses to morphine. Psychoneuroendocrinology 31, 653-663.

Di Chiara, G. (2002). Nucleus accumbens shell and core dopamine: differential role in behavior and addiction. Behav. Brain Res. 137, 75-114.

Dinieri, J. A., Nemeth, C. L., Parsegian, A., Carle, T., Gurevich, V. V., Gurevich, E., Neve, R. L., Nestler, E. J., and Carlezon, W. A. Jr. (2009). Altered sensitivity to rewarding and aversive drugs in mice with inducible disruption of cAMP response elementbinding protein function within the nucleus accumbens. J. Neurosci. 29, 1855-1859.
Dworkin, S. I., Co, C., and Smith, J. E. (1995). Rat brain neurotransmitter turnover rates altered during withdrawal from chronic cocaine administration. Brain Res. 682, 116-126.

Eiden, R. D. (2001). Maternal substance use and mother-infant feeding interactions. Infant Ment. Health J. 22, 497-511.

Eiden, R. D., Stevens, A., Schuetze, P., and Dombkowski, L. E. (2006). A conceptual model for maternal behavior among polydrug cocaineusing mothers: the role of postnatal cocaine use and maternal depression. Psychol. Addict. Behav. 20, $1-10$.

Elliott, J. C., Lubin, D. A., Walker, C. H., and Johns, J. M. (2001). Acute cocaine alters oxytocin levels in the medial preoptic area and amygdala in lactating rat dams: implications for cocaine-induced changes in maternal behavior and maternal aggression. Neuropeptides 35, 127-134.

Erb, S. (2010). Evaluation of the relationship between anxiety during withdrawal and stress-induced reinstatement of cocaine seeking. Prog. Neuropsychopharmacol. Biol. Psychiatry 34, 798-807.

Febo, M., Felix-Ortiz, A. C., and Johnson, T. R. (2010). Inactivation or inhibition of neuronal activity in the medial prefrontal cortex largely reduces pup retrieval and grouping in maternal rats. Brain Res. 1325 , 77-88.

Febo, M., and Ferris, C. F. (2007). Development of cocaine sensitization before pregnancy affects subsequent maternal retrieval of pups and prefrontal cortical activity during nursing. Neuroscience 148 , 400-412.

Febo, M., Numan, M., and Ferris, C. F. (2005). Functional magnetic resonance imaging shows oxytocin activates brain regions associated with mother-pup bonding during suckling. J. Neurosci. 25 , 11637-11644.

Febo, M., Segarra, A. C., Nair, G., Schmidt, K., Duong, T. Q., and Ferris, C. F. (2004). The neural consequences of repeated cocaine exposure revealed by functional MRI in awake rats. Neuropsychopharmacology 30, 936-943.

Feldman, R., Weller, A., ZagoorySharon, O., and Levine, A. (2007). Evidence for a neuroendocrinological foundation of human affiliation: plasma oxytocin levels across pregnancy and the postpartum period predict mother-infant bonding. Psychol. Sci. 18, 965-970.
Felton, T. M., Linton, L., Rosenblatt, J. S., and Morrell, J. I. (1998). Intact neurons of the lateral habenular nucleus are necessary for the nonhormonal, pup-mediated display of maternal behavior in sensitized virgin female rats. Behav. Neurosci. 112, 1458-1465.

Ferguson, J. N., Aldag, J. M., Insel, T. R., and Young, L. J. (2001). Oxytocin in the medial amygdala is essential for social recognition in the mouse. $J$. Neurosci. 21, 8278-8285.

Ferguson, J. N., Young, L. J., Hearn, E. F., Matzuk, M. M., Insel, T. R., and Winslow, J. T. (2000). Social amnesia in mice lacking the oxytocin gene. Nat. Genet. 25, 284-288.

Ferris, C. F., Kulkarni, P., Sullivan, J. M. Jr., Harder, J. A., Messenger, T. L., and Febo, M. (2005). Pup suckling is more rewarding than cocaine: evidence from functional magnetic resonance imaging and three-dimensional computational analysis. J. Neurosci. 25, 149-156.

Fleming, A. S., and Korsmit, M. (1996). Plasticity in the maternal circuit: effects of maternal experience on Fos-Lir in hypothalamic, limbic, and cortical structures in the postpartum rat. Behav. Neurosci. 110, 567-582.

Fleming, A. S., Suh, E. J., Korsmit, M., and Rusak, B. (1994a). Activation of Fos-like immunoreactivity in the medial preoptic area and limbic structures by maternal and social interactions in rats. Behav. Neurosci. $108,724-734$

Fleming, A. S., and Walsh, C. (1994b) Neuropsychology of maternal behavior in the rat: c-fos expression during mother-litter interactions. Psychoneuroendocrinology 429-443.

Franklin, T. R., and Druhan, J. P. (2000). Expression of Fos-related antigens in the nucleus accumbens and associated regions following exposure to a cocaine-paired environment. Eur. J. Neurosci. 12, 2097-2106.

Freeman, W. M., Brebner, K., Lynch, W. J., Robertson, D. J., Roberts, D. C., and Vrana, K. E. (2001). Cocaineresponsive gene expression changes in rat hippocampus. Neuroscience 108, 371-380.

Freeman, W. M., Lull, M. E., Patel, K. M., Brucklacher, R. M., Morgan, D., Roberts, D. C., and Vrana, K. E. (2010). Gene expression changes in the medial prefrontal cortex and nucleus accumbens following abstinence from cocaine selfadministration. BMC Neurosci. 11, 29. doi: 10.1186/1471-2202-11-29 
Gammie, S. C., Bethea, E. D., and Stevenson, S. A. (2007). Altered maternal profiles in corticotropinreleasing factor receptor 1 deficient mice. BMC Neurosci. 8, 17. doi: 10.1186/1471-2202-8-17

Gammie, S. C., Edelmann, M. N., Mandel-Brehm, C., D’Anna, K. L., Auger, A. P., and Stevenson, S. A. (2008a). Altered dopamine signaling in naturally occurring maternal neglect. PLoS ONE 3, e1974. doi: 10.1371/journal.pone.0001974

Gammie, S. C., Seasholtz, A. F., and Stevenson, S. A. (2008b). Deletion of corticotropin-releasing factor binding protein selectively impairs maternal, but not intermale aggression. Neuroscience 157, 502512.

Geisler, S., and Trimble, M. (2008). The lateral habenula: no longer neglected. CNS Spectr. 13, 484-489.

Goeders, N. E. (2002). Stress and cocaine addiction. J. Pharmacol. Exp. Ther. 301, 785-789.

Gottwald, S. R., and Thurman, S. K. (1994). The effects of prenatal cocaine exposure on mother-infant interaction and infant arousal in the newborn period. Topics Early Child. Spec. Educ. 14, 217-231.

Gulpinar, M. A., and Yegen, B. C. (2004). The physiology of learning and memory: role of peptides and stress. Curr. Protein Pept. Sci. 5, 457-473.

Haber, S. N., and Knutson, B. (2009). The reward circuit: linking primate anatomy and human imaging. Neuropsychopharmacology 35, 4-26.

Hammer, R. P. Jr., and Cooke, E. S. (1994). Gradual tolerance of metabolic activity is produced in mesolimbic regions by chronic cocaine treatment, while subsequent cocaine challenge activates extrapyramidal regions of rat brain. J. Neurosci. 14, 4289-4298.

Hatton, G. I., and Wang, Y. F. (2008). Neural mechanisms underlying the milk ejection burst and reflex. Prog. Brain Res. 170, 155-166.

Heiming, R. S., and Sachser, N. (2010). Consequences of serotonin transporter genotype and early adversity on behavioral profile - pathology or adaptation? Front. Neurosci. 4:187. doi: 10.3389/fnins.2010.00187

Herman, J. P., Ostrander, M. M., Mueller, N. K., and Figueiredo, H. (2005). Limbic system mechanisms of stress regulation: hypothalamopituitary-adrenocortical axis. Prog. Neuropsychopharmacol. Biol. Psychiatry 29, 1201-1213.

Hernandez-Gonzalez, M., PrietoBeracoechea, C., Navarro-Meza, M.,
Ramos-Guevara, J. P., Reyes-Cortes, R., and Guevara, M. A. (2005). Prefrontal and tegmental electrical activity during olfactory stimulation in virgin and lactating rats. Physiol. Behav. 83, 749-758.

Insel, T. R. (2003). Is social attachment an addictive disorder? Physiol. Behav. 79, 351-357.

Jarrett, T. M., McMurray, M. S., Walker, C. H., and Johns, J. M. (2006) Cocaine treatment alters oxytocin receptor binding but not mRNA production in postpartum rat dams. Neuropeptides 40, 161-167.

Jin, S. H., Blendy, J. A., and Thomas, S. A. (2005). Cyclic AMP response element-binding protein is required for normal maternal nurturing behavior. Neuroscience 133, 647-655.

Johns, J. M., Elliott, D. L., Hofler, V. E., Joyner, P. W., McMurray, M. S., and Jarrett, T. M., Haslup, A. M., Middleton, C. L., Elliott, J. C., and Walker, C. H. (2005). Cocaine treatment and prenatal environment interact to disrupt intergenerational maternal behavior in rats. Behav. Neurosci. 119, 1605-1618.

Johns, J. M., Lubin, D. A., Walker, C. H., Joyner, P., Middleton, C., Hofler, V., and McMurray, M. (2004). Gestational treatment with cocaine and fluoxetine alters oxytocin receptor number and binding affinity in lactating rat dams. Int. J. Dev. Neurosci. 22, 321-328.

Johns, J. M., Lubin, D. A., Walker, C. H., Meter, K. E., and Mason, G. A. (1997a). Chronic gestational cocaine treatment decreases oxytocin levels in the medial preoptic area, ventral tegmental area and hippocampus in Sprague-Dawley rats. Neuropeptides 31, 439-443.

Johns, J. M., Noonan, L. R., Zimmerman, L. I., Li, L., and Pedersen, C. A. (1997b). Effects of shortand long- term withdrawal from gestational cocaine treatment on maternal behavior and aggression in Sprague-Dawley rats. Dev. Neurosci. 19, 368-374.

Johns, J. M., Noonan, L. R., Zimmerman, L. I., Li, L., and Pedersen, C. A. (1994). Effects of chronic and acute cocaine treatment on the onset of maternal behavior and aggression in Sprague-Dawley rats. Behav. Neurosci. 108, 107-112.

Johnson, A. L., Morrow, C. E., Accornero, V. H., Xue, L., Anthony, J. C., and Bandstra, E. S. (2002). Maternal cocaine use: estimated effects on mother-child play interactions in the preschool period. J. Dev. Behav. Pediatr. 23, 191-202.
Kash, T. L., Nobis, W. P., Matthews, R. T., and Winder, D. G. (2008). Dopamine enhances fast excitatory synaptic transmission in the extended amygdala by a CRF-R1dependent process. J. Neurosci. 28, 13856-13865.

Kelley, S. J. (1998). Stress and coping behaviors of substance-abusing mothers. J. Soc. Pediatr. Nurs. 3, 103-110.

Kimble, D. P., Rogers, L., and Hendrickson, C. W. (1967). Hippocampal lesions disrupt maternal, not sexual behavior in the albino rat. $J$. Comp. Physiol. Psychol. 63, 401-407.

Kinnally, E. L., Tarara, E. R., Mason, W. A., Mendoza, S. P., Abel, K., Lyons, L. A., and Capitanio, J. P. (2009). Serotonin transporter expression is predicted by early life stress and is associated with disinhibited behavior in infant rhesus macaques. Genes Brain Behav. 9, 45-52.

Knutson, B., and Cooper, J. C. (2005). Functional magnetic resonance imaging of reward prediction. Curr. Opin. Neurol. 18, 411-417.

Koob, G. F., and Volkow, N. D. (2010). Neurocircuitry of addiction. Neuropsychopharmacology 35, 217-238.

Kreibich, A. S., and Blendy, J. A. (2004). cAMP response elementbinding protein is required for stress but not cocaine-induced reinstatement. J. Neurosci. 24, 6686-6692.

Kreibich, A. S., Briand, L., Cleck, J. N., Ecke, L., Rice, K. C., and Blendy, J. A. (2009). Stress-induced potentiation of cocaine reward: a role for CRF R1 and CREB. Neuropsychopharmacology 34, 2609-2617.

Kringelbach, M. L., Lehtonen, A., Squire, S., Harvey, A. G., Craske, M. G., Holliday, I. E., Green, A. L., Aziz, T. Z., Hansen, P. C., Cornelissen, P. L. and Stein, A. (2008). A specific and rapid neural signature for parental instinct. PLoS ONE 3, e1664. doi: 10.1371/journal.pone.0001664

Kuczkowski, K. (2004). The cocaine abusing parturient: a review of anesthetic considerations. Can. J. Anesth. 51, 145-154.

Lau, C., and Simpson, C. (2004). Animal models for the study of the effect of prolonged stress on lactation in rats. Physiol. Behav. 82, 193-197.

Le Moal, M. (2009). Drug abuse: vulnerability and transition to addiction. Pharmacopsychiatry 42, S42-S55.

Lee, A., Clancy, S., and Fleming, A. S. (2000). Mother rats bar-press for pups: effects of lesions of the mpoa and limbic sites on maternal behavior and operant responding for pup- reinforcement. Behav. Brain Res. 108, 215-231. [Corrected and republished article originally printed in Behav. Brain Res. 1999; 100, 15-31].

Lee, H. J., Macbeth, A. H., Pagani, J. H., and Young, W. S. III. (2009). Oxytocin: the great facilitator of life. Prog. Neurobiol. 88, 127-151.

Li, M., and Fleming, A. S. (2003). The nucleus accumbens shell is critical for normal expression of pupretrieval in postpartum female rats. Behav. Brain Res. 145, 99-111.

Li, M. Y., Yan, Q. S., Coffey, L. L., and Reith, M. E. (1996). Extracellular dopamine, norepinephrine, and serotonin in the nucleus accumbens of freely moving rats during intracerebral dialysis with cocaine and other monoamine uptake blockers. J. Neurochem. 66, 559-568.

Light, K. C., Grewen, K. M., Amico, J. A., Boccia, M., Brownley, K. A., and Johns, J. M. (2004). Deficits in plasma oxytocin responses and increased negative affect, stress, and blood pressure in mothers with cocaine exposure during pregnancy. Addict. Behav. 29, 1541-1564.

Lightman, S. L., Windle, R. J., Wood, S. A., Kershaw, Y. M., Shanks, N., and Ingram, C. D. (2001). Peripartum plasticity within the hypothalamopituitary-adrenal axis. Prog. Brain Res. 133, 111-129.

Lodge, D. J., and Grace, A. A. (2005). Acute and chronic corticotropinreleasing factor 1 receptor blockade inhibits cocaine-induced dopamine release: correlation with dopamine neuron activity. J. Pharmacol. Exp. Ther. 314, 201-206.

Lonstein, J. S., Simmons, D. A., and Stern, J. M. (1998). Functions of the caudal periaqueductal gray in lactating rats: kyphosis, lordosis, maternal aggression, and fearfulness. Behav. Neurosci. 112, 1502-1518.

Lonstein, J. S., and Stern, J. M. (1997). Role of the midbrain periaqueductal gray in maternal nurturance and aggression: $\mathrm{c}$-fos and electrolytic lesion studies in lactating rats. J. Neurosci. 17, 3364-3378.

Lorberbaum, J. P., Newman, J. D., Dubno, J. R., Horwitz, A. R., Nahas, Z., Teneback, C. C., Bloomer, C. W., Bohning, D. E., Vincent, D., Johnson, M. R., Emmanuel, N., BrawmanMintzer, O., Book, S. W., Lydiard, R. B., Ballenger, J. C., and George, M. S. (1999). Feasibility of using fMRI to study mothers responding to infant cries. Depress. Anxiety 10, 99-104.

Lorberbaum, J. P., Newman, J. D., Horwitz, A. R., Dubno, J. R., Lydiard, R. B., Hamner, M. B., Bohning, D. E., and George, M. S. (2002). A potential role for thalamocingulate circuitry in human maternal behavior. Biol. Psychiatry 51, 431-445. 
Lovic, V., Palombo, D. J., and Fleming, A. S. (2010). Impulsive rats are less maternal. Dev. Psychobiol. 53, 13-22.

Lubin, D. A., Cannon, J. B., Black, M. C., Brown, L. E., and Johns, J. M. (2003). Effects of chronic cocaine on monoamine levels in discrete brain structures of lactating rat dams. Pharmacol. Biochem. Behav. 74, 449-454.

Lubin, D. A., Meter, K. E., Walker, C. H., and Johns, J. M. (2001). Effects of chronic cocaine administration on aggressive behavior in virgin rats. Prog. Neuropsychopharmacol. Biol. Psychol. 25, 1421-1433.

Mattson, B. J., and Morrell, J. I. (2005). Preference for cocaine- versus pupassociated cues differentially activates neurons expressing either Fos or cocaine- and amphetamineregulated transcript in lactating, maternal rodents. Neuroscience 135, 315-328.

Mayes, L. C., Feldman, R., Granger, R. H., Haynes, O. M., Bornstein, M. H., and Schottenfeld, R. (1997). The effects of polydrug use with and without cocaine on mother-infant interaction at 3 and 6 months. Infant Behav. Dev. 20, 489-502.

McClure, S. M., York, M. K., and Montague, P. R. (2004). The neural substrates of reward processing in humans: the modern role of fMRI. Neuroscientist 10, 260-268.

McEwen, B. S., and Gianaros, P. J. (2011). Stress- and allostasisinduced brain plasticity. Annu. Rev. Med. 62, 431-445.

McMurray, M. S., Joyner, P. W., Middleton, C. W., Jarrett, T. M., Elliott, D. L., Black, M. A., Hofler, V. E., Walker, C. H., and Johns, J. M. (2008). Intergenerational effects of cocaine on maternal aggressive behavior and brain oxytocin in rat dams. Stress 11 , 398-410.

Meshul, C. K., Noguchi, K., Emre, N., and Ellison, G. (1998). Cocaineinduced changes in glutamate and GABA immunolabeling within rat habenula and nucleus accumbens. Synapse 30, 211-220.

Molitor, A., and Mayes, L. C. (2010). Problematic dyadic interaction among toddlers and their polydrugcocaine-using mothers. Infant Ment. Health J. 31, 121-140.

Nelson, C. J., Meter, K. E., Walker, C. H., Ayers, A. A., and Johns, J. M. (1998). A dose-response study of chronic cocaine on maternal behavior in rats. Neurotoxicol. Teratol. 20, 657-660.

Nephew, B. C., and Febo, M. (2010). Effect of cocaine sensitization prior to pregnancy on maternal care and aggression in the rat.
Psychopharmacology (Berl.) 209, 127-135.

Nitschke, J. B., Nelson, E. E., Rusch, B. D., Fox, A. S., Oakes, T. R., and Davidson, R. J. (2004). Orbitofrontal cortex tracks positive mood in mothers viewing pictures of their newborn infants. Neuroimage 21, 583-592.

Noriuchi, M., Kikuchi, Y., and Senoo, A. (2008). The functional neuroanatomy of maternal love: mother's response to infant's attachment behaviors. Biol. Psychiatry 63, 415-423.

Numan, M. (2007). Motivational systems and the neural circuitry of maternal behavior in the rat. Dev. Psychobiol. 49, 12-21.

Numan, M., Stolzenberg, D. S., Dellevigne, A. A., Correnti, C. M., and Numan, M. J. (2009). Temporary inactivation of ventral tegmental area neurons with either muscimol or baclofen reversibly disrupts maternal behavior in rats through different underlying mechanisms. Behav. Neurosci. 123, 740-751.

Olazabal, D. E., Abercrombie, E., Rosenblatt, J. S., and Morrell, J. I. (2004). The content of dopamine, serotonin, and their metabolites in the neural circuit that mediates maternal behavior in juvenile and adult rats. Brain Res. Bull. 63, 259-268.

Oleson, E. B., Talluri, S., Childers, S. R., Smith, J. E., Roberts, D. C., Bonin, K. D., and Budygin, E. A. (2009). Dopamine uptake changes associated with cocaine self-administration. Neuropsychopharmacology 34 1174-1184.

Pajulo, M., Suchman, N., Kalland, M., and Mayes, L. (2006). Enhancing the effectiveness of residential treatment for substance abusing pregnant and parenting women: focus on maternal reflective functioning and mother-child relationship. Infant Ment. Health J. 27, 448.

Palkovits, M., Young, W. S. III, Kovacs, K., Toth, Z., and Makara, G. B. (1998). Alterations in corticotropinreleasing hormone gene expression of central amygdaloid neurons following long-term paraventricular lesions and adrenalectomy. Neuroscience $85,135-147$.

Panatier, A., and Oliet, S. H. (2006). Neuron-glia interactions in the hypothalamus. Neuron Glia Biol. 2, 51-58.

Pawluski, J. L., and Galea, L. A. (2007). Reproductive experience alters hippocampal neurogenesis during the postpartum period in the dam. Neuroscience $149,53-67$.
Paxinos, G., and Watson, C. (1997). "The Rat Brain", in Stereotaxic Coordinates. San Diego: Academic Press.

Pedersen, C. A., and Boccia, M. L. (2002). Oxytocin links mothering received, mothering bestowed and adult stress responses. Stress 5, 259-267.

Pedersen, C. A., Caldwell, J. D., Walker, C., Ayers, G., and Mason, G. A. (1994). Oxytocin activates the postpartum onset of rat maternal behavior in the ventral tegmental and medial preoptic areas. Behav. Neurosci. 108, 1163-1171.

Pego, J. M., Morgado, P., Pinto, L. G., Cerqueira, J. J., Almeida, O. F., and Sousa, N. (2008). Dissociation of the morphological correlates of stressinduced anxiety and fear. Eur. J. Neurosci. 27, 1503-1516.

Peterson, S. L., Olsta, S. A., and Matthews, R. T. (1990). Cocaine enhances medial prefrontal cortex neuron response to ventral tegmental area activation. Brain Res. Bull. 24, 267-273.

Quinones-Jenab, V., Krey, L. C., Schlussman, S. D., Ho, A., and Kreek, M. J. (2000). Chronic 'binge' pattern cocaine alters the neuroendocrine profile of pregnant rats. Neurosci. Lett. 282, 120-122.

Rasia-Filho, A. A., Londero, R. G. and Achaval, M. (2000). Functional activities of the amygdala: an overview. J. Psychiatry Neurosci. 25, 14-23.

Rees, S. L., Panesar, S., Steiner, M., and Fleming, A. S. (2004). The effects of adrenalectomy and corticosterone replacement on maternal behavior in the postpartum rat. Horm. Behav. 46, 411-419.

Rodaros, D., Caruana, D. A., Amir, S., and Stewart, J. (2007). Corticotropin-releasing factor projections from limbic forebrain and paraventricular nucleus of the hypothalamus to the region of the ventral tegmental area. Neuroscience 150, 8-13.

Russo, S. J., Dietz, D. M., Dumitriu, D., Morrison, J. H., Malenka, R. C., and Nestler, E. J. (2010). The addicted synapse: mechanisms of synaptic and structural plasticity in nucleus accumbens. Trends Neurosci. 33, 267-276.

Russo, S. J., Festa, E. D., Fabian, S. J. Gazi, F. M., Kraish, M., Jenab, S., and Quiñones-Jenab, V. (2003). Gonadal hormones differentially modulate cocaine-induced conditioned place preference in male and female rats. Neuroscience 120, 523-533.

Seip, K. M., and Morrell, J. I. (2007). Increasing the incentive salience of cocaine challenges preference for pup- over cocaine-associated stimuli during early postpartum: place preference and locomotor analyses in the lactating female rat. Psychopharmacology (Berl.) 194, 309-319.

Seip, K. M., and Morrell, J. I. (2009). Transient inactivation of the ventral tegmental area selectively disrupts the expression of conditioned place preference for pup- but not cocainepaired contexts. Behav. Neurosci. 123, 1325-1338.

Seip, K. M., Pereira, M., Wansaw, M. P., Reiss, J. I., Dziopa, E. I., and Morrell, J. I. (2008). Incentive salience of cocaine across the postpartum period of the female rat. Psychopharmacology (Berl.) 199, 119-130.

Sesack, S. R., and Grace, A. A. (2010). Cortico-basal ganglia reward network: microcircuitry. Neuropsychopharmacology 35, 27-47.

Shahrokh, D. K., Zhang, T. Y., Diorio, J., Gratton, A., and Meaney, M. J. (2010). Oxytocin-dopamine interactions mediate variations in maternal behavior in the rat. Endocrinology 151, 2276-2286.

Sinha, R. (2001). How does stress increase risk of drug abuse and relapse? Psychopharmacologia 158, 343-359.

Sinha, R., Lacadie, C., Skudlarski, P., Fulbright, R., Rounsaville, B., Kosten, T., and Wexler, B. E. (2005). Neural activity associated with stress-induced cocaine craving: a functional magnetic resonance imaging study. Psychopharmacology (Berl.) 183, 171-180.

Sinha, R., Lacadie, C., Skudlarski, P., and Wexler, B. E. (2004). Neural circuits underlying emotional distress in humans. Ann. N. Y. Acad. Sci. 1032, 254-257.

Sinha, R., and Li, C. S. R. (2007). Imaging stress- and cue-induced drug and alcohol craving: association with relapse and clinical implications. Drug Alcohol Rev. 26, 25-31.

Slattery, D. A., and Neumann, I. D. (2008). No stress please! Mechanisms of stress hyporesponsiveness of the maternal brain. J. Physiol. 586, 377-385.

Smith, J. W., Seckl, J. R., Evans, A. T., Costall, B., and Smythe, J. W. (2004). Gestational stress induces post-partum depression-like behaviour and alters maternal care in rats. Psychoneuroendocrinology 29, 227-244.

Sombers, L. A., Beyene, M., Carelli, R. M., and Wightman, R. M. (2009). Synaptic overflow of dopamine in the nucleus accumbens arises from neuronal activity in the ventral tegmental area. J. Neurosci. 29, 1735-1742. 
Stack, E. C., Balakrishnan, R., Numan, M. J., and Numan, M. (2002). A functional neuroanatomical investigation of the role of the medial preoptic area in neural circuits regulating maternal behavior. Behav. Brain Res. 131, 17-36.

Steffensen, S. C., Taylor, S. R., Horton, M. L., Barber, E. N., Lyle, L. T., Stobbs, S. H., and Allison, D. W. (2008). Cocaine disinhibits dopamine neurons in the ventral tegmental area via use-dependent blockade of GABA neuron voltagesensitive sodium channels. Eur. J. Neurosci. 28, 2028-2040.

Strathearn, L., Fonagy, P., Amico, J., and Montague, P. R. (2009). Adult attachment predicts maternal brain and oxytocin response to infant cues. Neuropsychopharmacology 34, 2655-2666.

Strathearn, L., and Kosten, T. R. (2008). Does chronic cocaine use affect a mother's brain response to baby face cues? A pilot fMRI study. The College on Problems of Drug Dependence 70th Annual Scientific Meeting.

Substance Abuse and Mental Health Services Administration. (2008). Results from the 2007 National Survey on Drug Use and Health: National Findings (Office of Applied Studies, NSDUH Series H-34, DHHS Publication No. SMA 08-4343). Rockville, MD.

Suchman, N., Decoste, C., Castiglioni, N., Legow, N., and Mayes, L. (2008). THE MOTHERS AND TODDLERS PROGRAM: preliminary findings from an attachment-based parenting intervention for substanceabusing mothers. Psychoanal. Psychol. 25.

Suchman, N. E., and Luthar, S. S. (2001). The mediating role of parenting stress in methadonemaintained mothers' parenting. Par ent Sci. Pract. 1, 285-315.

Takayanagi, Y., Yoshida, M., Bielsky, I. F., Ross, H. E., Kawamata, M., Onaka, T., Yanagisawa, T., Kimura, T., Matzuk, M. M., Young, L. J., and Nishimori, K. (2005). Pervasive social deficits, but normal parturition, in oxytocin receptor-deficient mice. Proc. Natl. Acad. Sci. U.S.A. 102, 16096-16101.

Thomas, M. J., and Malenka, R. C. (2003). Synaptic plasticity in the mesolimbic dopamine system. Philos. Trans. R. Soc. Lond. B Biol. Sci. 358, 815-819.

Thompson, A. C., and Kristal, M. B. (1996). Opioid stimulation in the ventral tegmental area facilitates the onset of maternal behavior in rats. Brain Res. 743, 184-201.

Tronick, E. Z., Messinger, D. S., Weinberg, M. K., Lester, B. M., LaGasse, L., Seifer, R., Bauer, C. R., Shankaran, S., Bada, H., Wright, L. L., Poole, K., and Liu, J. (2005). Cocaine exposure is associated with subtle compromises of infants' and mothers' socialemotional behavior and dyadic features of their interaction in the faceto-face still-face paradigm. Dev. Psychol. 41, 711-722.

Uhlhorn, S. B., Messinger, D. S., and Bauer, C. R. (2005). Cocaine exposure and mother-toddler social play. Infant Behav. Dev. 28, 62-73.

Uvnas-Moberg, K., Arn, I., and Magnusson, D. (2005). The psychobiology of emotion: the role of the oxytocinergic system. Int. J. Behav. Med. 12, 59-65.

Van den Oever, M. C., Spijker, S., Smit, A. B., and De Vries, T. J. (2010). Prefrontal cortex plasticity mechanisms in drug seeking and relapse. Neurosci. Biobehav. Rev. 25, 276-284.

van Velzen, A., and Toth, M. (2010). Role of maternal 5-HT(1A) receptor in programming offspring emotional and physical development. Genes Brain Behav. 9, 877-885.

Venkatesan, A., Nath, A., Ming, G. L., and Song, H. (2007). Adult hippocampal neurogenesis: regulation by HIV and drugs of abuse. Cell Mol. Life Sci. 64, 2120-2132.

Walker, D. L., Toufexis, D. J., and Davis, M. (2003). Role of the bed nucleus of the stria terminalis versus the amygdala in fear, stress, and anxiety. Eur. J. Pharmacol. 463, 199-216.

Webster-Stratton, C. (1990). Stress: a potential disruptor of parent perceptions and family interactions. J. Clin. Child Adolesc. Psychol. 19, 302-312.

Windle, R. J., Kershaw, Y. M., Shanks, N., Wood, S. A., Lightman, S. L., and Ingram, C. D. (2004). Oxytocin attenuates stress-induced c-fos mRNA expression in specific forebrain regions associated with modulation of hypothalamo-pituitaryadrenal activity. J. Neurosci. 24, 2974-2982.

Wise, R. A., and Morales, M. (2010). A ventral tegmental CRF-glutamatedopamine interaction in addiction. Brain Res. 1314, 38-43.

Yang, J. Y., Qi, J., Han, W. Y., Wang, F., and Wu, C. F. (2010). Inhibitory role of oxytocin in psychostimulantinduced psychological dependence and its effects on dopaminergic and glutaminergic transmission. Acta Pharmacol. Sin. 31, 1071-1074.

Yoshida, M., Takayanagi, Y., Inoue, K., Kimura, T., Young, L. J., Onaka, T., and Nishimori, $\mathrm{K}$.
(2009). Evidence that oxytocin exerts anxiolytic effects via oxytocin receptor expressed in serotonergic neurons in mice. J. Neurosci. 29, 2259-2271.

Zhang, D., Yang, S., Yang, C., Jin, G., and Zhen, X. (2008). Estrogen regulates responses of dopamine neurons in the ventral tegmental area to cocaine. Psychopharmacology (Berl.) 199, 625-635.

Zhao, C., and Li, M. (2010). c-Fos identification of neuroanatomical sites associated with haloperidol and clozapine disruption of maternal behavior in the rat. Neuroscience 166, 1043-1055.

Conflict of Interest Statement: The authors declare that the research was conducted in the absence of any commercial or financial relationships that could be construed as a potential conflict of interest.

Received: 22 February 2011; paper pending published: 06 April 2011; accepted: 09 June 2011; published online: 06 July 2011. Citation: Rutherford HJV, Williams SK, Moy S, Mayes LC and Johns JM (2011) Disruption of maternal parenting circuitry by addictive process: rewiring of reward and stress systems. Front. Psychiatry 2:37. doi: 10.3389/fpsyt.2011.00037 This article was submitted to Frontiers in Child and Neurodevelopmental Psychiatry, a specialty of Frontiers in Psychiatry. Copyright () 2011 Rutherford, Williams, Moy, Mayes and Johns. This is an openaccess article subject to a non-exclusive license between the authors and Frontiers Media SA, which permits use, distribution and reproduction in other forums, provided the original authors and source are credited and other Frontiers conditions are complied with. 